\title{
Netrin-G/NGL Complexes Encode Functional Synaptic Diversification
}

\author{
Hiroshi Matsukawa, ${ }^{1}$ Sachiko Akiyoshi-Nishimura, ${ }^{1}$ Qi Zhang, ${ }^{1}$ Rafael Luján, ${ }^{2}$ Kazuhiko Yamaguchi, ${ }^{1}$ Hiromichi Goto,${ }^{1}$ \\ Kunio Yaguchi, ${ }^{1}$ Tsutomu Hashikawa, ${ }^{3}$ Chie Sano, ${ }^{1}$ Ryuichi Shigemoto ${ }^{4,5}$ Toshiaki Nakashiba, ${ }^{1}$ and Shigeyoshi Itohara ${ }^{1}$ \\ ${ }^{1}$ Laboratory for Behavioral Genetics, RIKEN Brain Science Institute (BSI), Wako, Saitama, 351-0198, Japan, 2IDINE, Departamento de Ciencias Médicas, \\ Facultad de Medicina, Universidad Castilla-La Mancha, 13071 Albacete, Spain, ${ }^{3}$ Research Resource Center, RIKEN BSI, Wako, Saitama, 351-0198, Japan, \\ ${ }^{4}$ Division of Cerebral Structure, National Institute for Physiological Science, Okazaki 444-8787, Japan, and ${ }^{5}$ IST Austria, 3400 Klosterneuburg, Austria
}

Synaptic cell adhesion molecules are increasingly gaining attention for conferring specific properties to individual synapses. Netrin-G1 and netrin-G2 are trans-synaptic adhesion molecules that distribute on distinct axons, and their presence restricts the expression of their cognate receptors, NGL1 and NGL2, respectively, to specific subdendritic segments of target neurons. However, the neural circuits and functional roles of netrin-G isoform complexes remain unclear. Here, we use netrin-G-KO and NGL-KO mice to reveal that netrin-G1/ NGL1 and netrin-G2/NGL2 interactions specify excitatory synapses in independent hippocampal pathways. In the hippocampal CA1 area, netrin-G1/NGL1 and netrin-G2/NGL2 were expressed in the temporoammonic and Schaffer collateral pathways, respectively. The lack of presynaptic netrin-Gs led to the dispersion of NGLs from postsynaptic membranes. In accord, netrin-G mutant synapses displayed opposing phenotypes in long-term and short-term plasticity through discrete biochemical pathways. The plasticity phenotypes in netrinG-KOs were phenocopied in NGL-KOs, with a corresponding loss of netrin-Gs from presynaptic membranes. Our findings show that netrin-G/NGL interactions differentially control synaptic plasticity in distinct circuits via retrograde signaling mechanisms and explain how synaptic inputs are diversified to control neuronal activity.

Key words: excitatory synapse; mice; netrin-G1; netrin-G2; pathway specificity; trans-synaptic adhesion molecule

\section{Introduction}

Information processing in the brain depends on proper neuronal connectivity, which rests on a foundation of synaptic communication. For precise information processing between connected neurons, individual neurons express a variety of synaptic molecules that constitute functional assemblies necessary for the maturation of synaptic connectivity (Sheng and Kim, 2011; Südhof, 2012). Accumulating evidence suggests that synaptic cell adhesion proteins serve not only to maintain aligned synaptic membrane structures but also to control presynaptic and postsynaptic properties (Yamagata et al., 2003; Dalva et al., 2007; Han and Kim, 2008; Siddiqui and Craig, 2011). For example, neuroligin-1 and neuroligin-2 in vertebrates are preferentially distributed

\footnotetext{
Received March 21, 2014; revised 0ct. 1, 2014; accepted 0ct. 8, 2014.

Author contributions: H.M. and S.I. designed research; H.M., S.A.-N., Q.Z., R.L., K. Yamaguchi, H.G., T.H., C.S., and T.N. performed research; S.A.-N., Q.Z., K. Yaguchi, R.S., and S.I. contributed unpublished reagents/analytic tools; H.M., K. Yamaguchi, T.H., R.S., T.N., and S.I. analyzed data; H.M., T.N., and S.I. wrote the paper.

This work was supported by "Funding Program for World-Leading Innovative R\&D on Science and Technology (FIRST Program)" initiated by the Council for Science and Technology Policy. We thank Charles Yokoyama and Alexandra Terashima for their help in editing this manuscript; Yasunori Hayashi and Yukiko Goda for reading this manuscript; the staff of the Research Resources Center of the RIKEN Brain Science Institute for animal care and technical support; and, Takuji Iwasato, Reiko Ando, and all members of the Laboratory for Behavioral Genetics for stimulating discussion and technical support. We thank Ryohei Iwata for his help in Gene Gun-aided experiments. H.M. deeply thanks Masaki Kameyama for his continuous encouragement and discussion.

The authors declare no competing financial interests.

Correspondence should be addressed to Shigeyoshi Itohara, Laboratory for Behavioral Genetics, RIKEN, Brain Science Institute, Wako, Saitama, 351-0198, Japan. E-mail: sitohara@brain.riken.jp.

DOI:10.1523/JNEUROSCI.1141-14.2014

Copyright $\odot 2014$ the authors $\quad 0270-6474 / 14 / 3415779-14 \$ 15.00 / 0$
}

onto excitatory and inhibitory postsynaptic membranes, respectively, and thus differentially regulate excitatory and inhibitory responses (Chubykin et al., 2007; Blundell et al., 2010). Another class of cognate trans-synaptic ligand/receptor pairs, netrin-Gs/ NGLs, is thought to have a unique role in neural circuit functions elaborated in vertebrates. Netrin-G1 and netrin-G2 (also known as laminet1 and laminet2) are vertebrate-specific and glycosylphosphatidylinositol (GPI)-anchored subfamily members of the UNC-6/netrin family (Nakashiba et al., 2000, 2002; Yin et al., 2002). NGL1 and NGL2 (also known as LRRC4c and LRRC4) are vertebrate-specific and are type I transmembrane proteins containing a C-terminal intracellular postsynaptic density-95/disks large/zona occludens-1 (PDZ) binding motif, which interacts with scaffolding proteins such as PSD-95 family members (Lin et al., 2003; Kim et al., 2006; Woo et al., 2009). Netrin-G1 and netrin-G2 selectively bind to NGL1 and NGL2, respectively. Crystallographic complex studies confirmed the direct contact of those proteins (Seiradake et al., 2011). In cultured neurons, exogenous NGLs induce presynaptic differentiation and netrin-G clustering (Kim et al., 2006; Song et al., 2013). During development, NGL2 deletion leads to a lower spine density in hippocampal pyramidal neurons (DeNardo et al., 2012). Netrin-G1 and netrin-G2 are expressed in complementary neuron groups (Nakashiba et al., 2002; Yin et al., 2002; Nishimura-Akiyoshi et al., 2007; Woo et al., 2009), and distribute on axons segregated differentially along cortical laminar structures (Nakashiba et al., 2002; Nishimura-Akiyoshi et al., 2007). Axonal netrin-G1 and 
netrin-G2 constrain NGL1 and NGL2, respectively, into subdendritic segments to establish circuit specificity in a single neuron. This suggests that netrin-G/NGL trans-synaptic interactions help to diversify information processing. However, the role of netrinGs/NGLs interactions in synaptic functions remains largely unknown.

Here we studied the roles of netrin-G1/NGL1 and netrin-G2/ NGL2 interactions in hippocampal excitatory circuits using a full set of KO mice for netrin-Gs and NGLs. Immunoelectron microscopy (iEM) supported the requirement of these ligand/receptor pairs to stably localize presynaptic netrin-Gs and postsynaptic NGLs in a pathway-selective manner. Moreover, netrin-G/NGL transsynaptic interactions regulate synaptic plasticity by a retrograde signaling mechanism. These data reveal the significance of netrin-Gs/ NGLs systems in vertebrate brain.

\section{Materials and Methods}

Animals. All experimental procedures were performed in accordance with the guidelines of the RIKEN Institutional Animal Care and Experimentation Committee. Netrin-G1 (Ntng1)-KO and netrin-G2 (Ntng2)-KO mice were generated previously and maintained as C57BL6J congenic heterozygotes (Nishimura-Akiyoshi et al., 2007). For NGL1 (Ngl1) disruption, short sequences including the translation initiation codon in the third exon were replaced with a loxP site. For NGL2 (Ngl2) disruption, the entire cording sequence and downstream exons were replaced with $N-L a c Z$ and a loxP site. NGL1-KO and NGL2-KO mice were generated by homologous recombination using C57BL6-derived embryonic stem cells, CMTI-2 (Merck Millipore), and MS12 (Kawase et al., 1994), respectively, and maintained as C57BL6J isogenic heterozygotes. Due to an inefficient recombination rate at the Ngll locus, a long targeting vector based on bacterial artificial chromosome was used. Technical details will be described elsewhere (K. Yaguchi and S.I.). In all cases, homozygous KO and WT control littermates were obtained by crossing the heterozygotes. Adult mice (3-11 months old, otherwise described) were used in the present study. Mouse genotypes were determined by PCR using primers as follows: Ntng1-1 (5'-GTCAAGATTCCTG TCGATCC-3'), Ntng1-2 (5'-AGGGTCTCCACAGGTAATATCC-3'), LacZ1 (5'-TCGGCGGTGAAATTATCGATGAGC-3'), LacZ3 (5' CCACAGCGGATGGTTCGGATAATGC-3'), Ntng2-1 (5'CTCTTCAC AATGAAAGCCAAG-3'), Ntng2-2 (5'-TGAAGATAACACGGAATC AGG-3'), Ntng2-3 (5'-GGAGGGTAACCTTGCAGATAG-3'), NGL1 WTf (5'-GATGACCTTACATCCACAGC-3'), NGL1WTr (5'-GAC GATTGTCAAAGAGTTCC-3'), NGL1KOf (5'-CAGTGGCAGGATTA TACACC-3'), NGL1KOr (5'-GCCGCCCTTTAGTGAGGGTT-3'), NGL2-1 (5' -AGCTCGGCCGAGCTCAACAC-3'), and NGL2-2 (5'-GG GGAGTCATATTTGAGTTTCC-3').

Primer pairs of Ntng1-1/Ntng1-2 and LacZ1/LacZ3 yielded 206 and $374 \mathrm{bp}$ fragments from the WT and netrin-G1-KO alleles, respectively. Ntng2-1/Ntng2-2/Ntng2-3 yielded 322 and $166 \mathrm{bp}$ fragments from the WT and netrin-G2-KO alleles, respectively. NGL1WTf/NGL1WTr and NGL1KOf/NGL1r yielded 395 and 805 bp fragments from the WT and NGL1-KO alleles, respectively. NGL2-1/NGL2-2 and LacZ1/LacZ3 yielded 645 and $374 \mathrm{bp}$ fragments from the WT and NGL2-KO alleles, respectively.

Primary antibody. Rabbit polyclonal antibodies for netrin-G1 and netrin-G2 (Nakashiba et al., 2002), mouse monoclonal antibody for netrin-G1 (Niimi et al., 2007), and rabbit polyclonal antibodies for NGL1 and NGL2 (Nishimura-Akiyoshi et al., 2007), were used.

Electron microscopy. For post-embedding iEM, adult mice were deeply anesthetized by intraperitoneal injection of 2.5\% Avertin (Sigma-Aldrich; $0.5 \mathrm{ml} / \mathrm{kg}$ body weight), and perfused with $0.1 \mathrm{M} \mathrm{PB}, \mathrm{pH} 7.4$, containing 4\% PFA (TAAB), $0.1 \%$ glutaraldehyde (GA; Nacalai), and $15 \%$ saturated picric acid (Nacalai). After $4-6 \mathrm{~h}$ post fix in $4 \%$ PFA- $0.1 \mathrm{M}$ $\mathrm{PB}$, the brains were coronally cut at $500 \mu \mathrm{m}$ using microslicer (LinearSlicer Pro7; Dosaka) and cryoprotected with 30\% sucrose- 0.1 м PB. After trimming the hippocampal tissues small pieces, they were quickly frozen by falling into liquid propane and cryosubstitution was performed with methanol and subsequently with Lowicryl (HM20) followed by polymerization. Ultrathin sections cut at $70 \mathrm{~nm}$ from Lowicryl (HM20)embedded blocks of a piece of hippocampus including CA1 and DG regions were picked up on coated nickel grids and incubated for $40 \mathrm{~min}$ at room temperature (RT) in a blocking solution (BS) consisting of $2 \%$ human serum albumin (Sigma) in 0.05 м TBST $(0.3 \%$ Triton X-100). The grids were incubated with rabbit antibodies against mouse netrinG1, netrin-G2, NGL1, and NGL2 at a concentration of $15-20 \mu \mathrm{g} / \mathrm{ml}$ in BS at $28^{\circ} \mathrm{C}$ overnight. After washing in TBS, the grids were incubated for $4-6 \mathrm{~h}$ at RT with goat anti-rabbit IgG conjugated to $10 \mathrm{~nm}$ colloidal gold particles (Nanoprobes) diluted 1:80 in BS. Ultrathin sections on the grids were counterstained with $1 \%$ uranyl acetate and Reynold's lead citrate.

For pre-embedding iEM, the mice were perfused with $4 \%$ PFA, $0.05 \%$ GA-0.1 M PB. After $4-6 \mathrm{~h}$ post fix in $4 \%$ PFA-0.1 M PB, the brains were coronally cut in $50-\mu \mathrm{m}$-thick slices, cryoprotected in $30 \%$ sucrose- $0.1 \mathrm{M}$ $\mathrm{PB}$, and freeze-thawed by dipping into liquid nitrogen for better antibody penetration. After washing in TBS, free-floating sections were incubated in $10 \%$ normal goat serum (NGS) diluted in TBS for $1 \mathrm{~h}$ at RT. Sections were then incubated with anti-netrin-G1 diluted 1:4000 $(\sim 0.1$ $\mu \mathrm{g} / \mathrm{ml}$ ) in $1 \%$ NGS-TBS for $>48 \mathrm{~h}$ at $4^{\circ} \mathrm{C}$. After several washes in TBS, the sections were incubated with goat anti-rabbit IgG coupled to $1.4 \mathrm{~nm}$ gold (Nanoprobes) diluted $1: 100$ in $1 \%$ NGS-TBS overnight at $4^{\circ} \mathrm{C}$. After several washes in PBS, the immunoreacted sections were post fixed in $1 \%$ GA-PBS for $10 \mathrm{~min}$. They were then washed in double distilled water, followed by silver enhancement of the gold particles with an HQ Silver kit (Nanoprobes). The sections were then treated with 1\% osmium tetraoxide- $0.1 \mathrm{M} \mathrm{PB}$, stained with $1 \%$ uranyl acetate, dehydrated, and flat embedded in Durcupan resin (Fluka) on glass slides. Ultrathin sections on the grids were counterstained with $1 \%$ uranyl acetate and Reynold's lead citrate. Ultrastructural analyses were performed in transmission EM (JEM-1010; JEOL).

For conventional transmission EM experiments, netrin-G1-KO, netrinG2-KO, and their WT littermates (males, 6 weeks old) were perfused with a physiologic saline $(2.5 \mathrm{ml})$ followed by a mixture of $2 \%$ PFA and $2.5 \%$ GA in $0.1 \mathrm{~m}$ cacodylate buffer, $\mathrm{pH} 7.4,25 \mathrm{ml}$, under deep anesthesia with $0.15-0.20 \mathrm{ml}$ of Nembutal (sodium pentobarbital; $50 \mathrm{mg} / \mathrm{ml}$ ). The brains were fixed further in $2.5 \% \mathrm{GA}$ at $4^{\circ} \mathrm{C}$ overnight. Then brain slices including left dorsal hippocampus were osmicated, dehydrated, and embedded in Epon. Coronally cut hippocampus was examined under the light microscope, and ultrathin sections from the identified hippocampal areas in each animal were metal stained with lead citrate and uranyl acetate and examined under the electron microscope (1200EX; JEOL). Electron micrographs were obtained from the middle layers of the CA1 stratum radiatum (SR) and stratum lacunosum moleculare (SLM) of the dorsal hippocampus.

Light microscopic immunohistochemistry. Free-floating brain sections (50 $\mu \mathrm{m}$ thick), which had been incubated with anti-netrin-G1 (1:4000) and anti-netrin-G2 (1:400) antibodies through the same procedure as described above in the pre-embedding protocol, were incubated with HRP-conjugated goat anti-rabbit IgG (Vector Laboratories) diluted 1:100 in $1 \%$ NGS-TBS overnight at $4^{\circ} \mathrm{C}$. After several washes in PBS, sections were infused with avidin-biotin peroxidase complex (ABCElite; Vector Laboratories) diluted 1:100 in PBS for $1 \mathrm{~h}$ at RT. After washing three times in PBS and subsequently in $50 \mathrm{~mm}$ Tris- $\mathrm{HCl}, \mathrm{pH}$ 7.4, the sections were then incubated in the same buffer including $0.02 \%$ $\mathrm{DAB}$ (Dojindo) for $5 \mathrm{~min}$. DAB reaction was initiated by $0.003 \%$ hydrogen peroxide and terminated by addition of excess amounts of PBS. The sections were mounted on surface-coated slides, dehydrated, and preserved in a quick-drying mounting medium (Eukitt) for later image acquisition. The bright-field images were taken with a digital slide scanner (NanoZoomer; Hamamatsu Photonics).

For double staining of netrin-G1 and netrin-G2, cryosections ( $40 \mu \mathrm{m}$ thick) were cut and incubated with rabbit polyclonal anti-netrin-G2 (1: $400)$ and mouse mAb for netrin-G1 (1:200) overnight at $4^{\circ} \mathrm{C}$. The sections were then incubated with a mixture of secondary antibodiesAlexa Fluor 546-conjugated anti-rabbit IgG (1:1000; Life Technologies) and Alexa Fluor 488-conjugated anti-mouse IgG (1:2000; Life Technologies)—for $2 \mathrm{~h}$ at RT, and counterstained with DAPI (1:10,000; Invitrogen). 
A

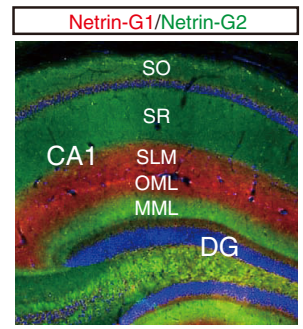

B
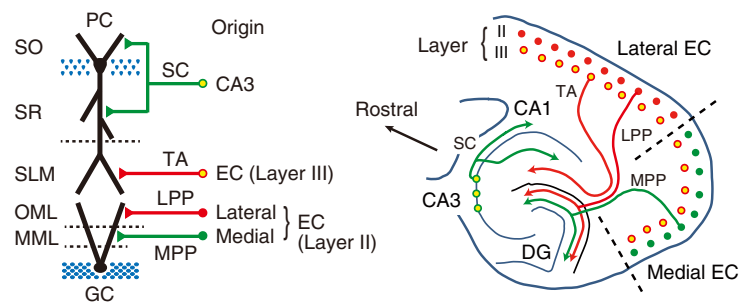

C
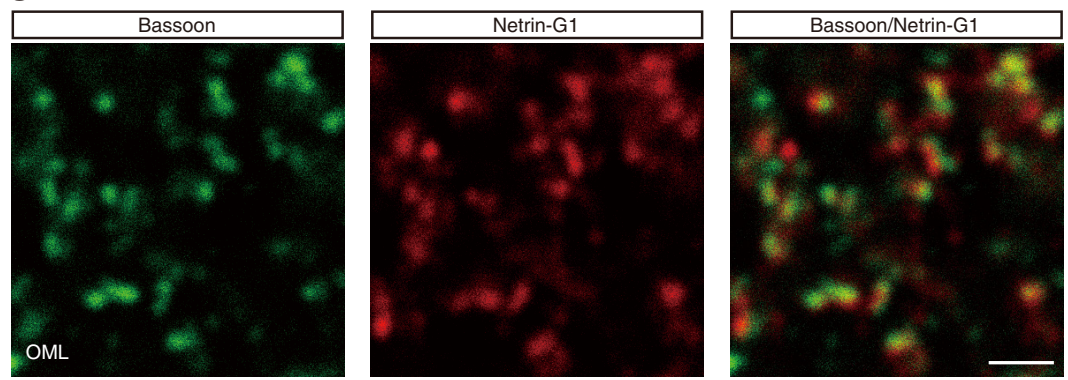

D
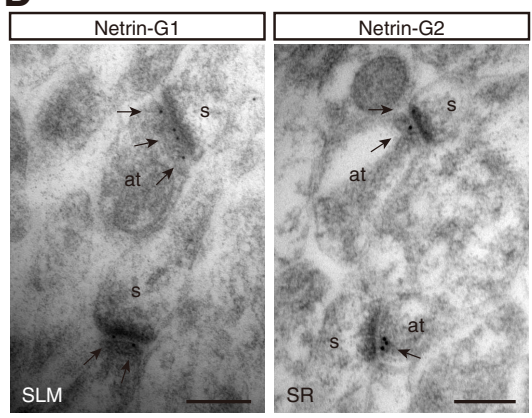

E
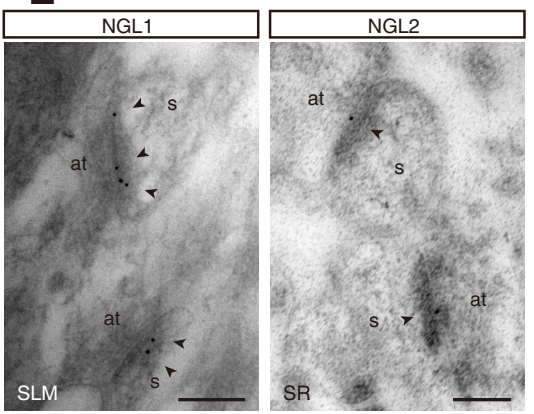

$\mathbf{F}$
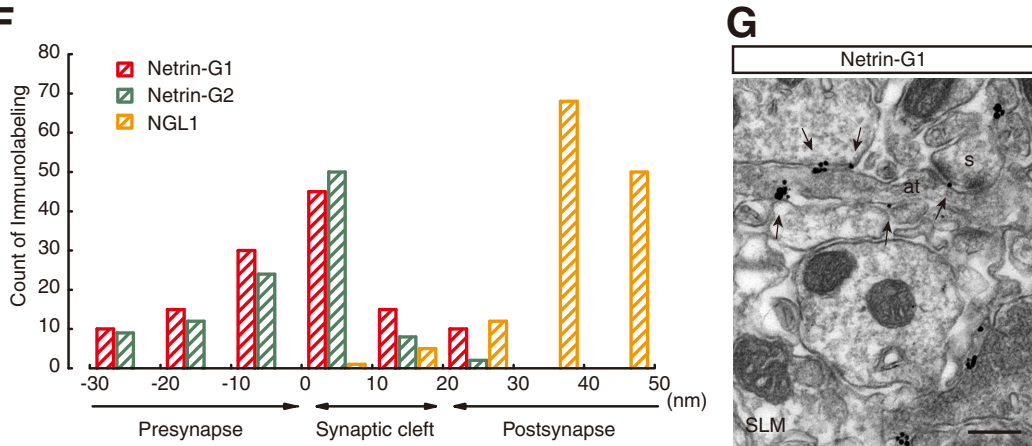

Figure 1. Presynaptic localization of netrin-G proteins and postsynaptic localization of NGL proteins in distinct hippocampal layers. $A$, Double-staining fluorescence image showing layer-selective distributions of netrin- $G$ subtypes in the hippocampal CA1 and DG regions. S0, stratum oriens. B, Schematics of entorhino-hippocampal/intrahippocampal projections expressing netrin-Gs (right) and the local synaptic connections (left). In the hippocampus, CA1 pyramidal and DG granule cells ( $P C$ and $G C$ ) receive netrin-G1 (red)-expressing and netrin- $G 2$ (green)-expressing inputs originating from entorhinal cortex (EC) layers II/III and CA3 areas. C, Confocal images showing double immunostaining for Bassoon and netrin-G1. Scale bar, $1 \mu \mathrm{m} . \boldsymbol{D}, \boldsymbol{E}$, Electron micrographs show immune signals for netrin-G1, netrin-G2, NGL1, and NGL2, as detected using a post-embedding immunogold technique. D, Immunogold particles (arrows) for netrin-G1 and netrin-G2 were detected mainly along the presynaptic axon terminals (at) making excitatory synapses on dendritic spines (s) of the pyramidal cells in SLM and SR, respectively. $\boldsymbol{E}$, Immunoparticles for NGL1 and NGL2 were mostly detected postsynaptically in the vicinity of the postsynaptic density of dendritic spines in SLM and SR, respectively. Scale bars, $200 \mathrm{~nm}$. $\boldsymbol{F}$, Relative distance of the immune particles to presynaptic membrane structure was allocated to $10 \mathrm{~nm}$ wide bins and expressed as counts. Positive location was defined as extracellular face from presynaptic terminal (at $0 \mathrm{~nm}$ ). Frequencies of particle distribution for netrin-G1 and netrin-G2 peaked within the synaptic cleft, while that of NGL1 nestled postsynaptically. The mean synaptic cleft size was $19.16 \mathrm{~nm}$, as determined by 17 representative synapses. G, A pre-embedding immunogold technique showed multiple immunoparticles for netrin-G1 (arrows) exclusively along the longitudinally running axon structure in SLM. Scale bar, $200 \mathrm{~nm}$.
Triple fluorescence images were captured and tiled to build a large-field image with a fluorescence microscope (BZ-X700; Keyence).

For double staining of netrin-G1 with Bassoon (mouse mAb VAM-PS003; StressGen), thin sections from paraffin-embedded samples were deparaffinized, rehydrated, and processed for heat-induced epitope retrieval. Blocking was done for $1 \mathrm{~h}$ at RT. Then the slices were incubated with primary antibodies for $12 \mathrm{~h}$ and fluorescence-conjugated secondary antibodies for $4 \mathrm{~h}$ at RT. The confocal images were captured with $100 \times$ oil lens by Leica TCS SP8 STED $3 \times$ microscope.

Dendrite morphology analysis. Mice were anesthetized with tribromoethanol (125 mg/ $\mathrm{kg}$, i.p.) and then perfused transcardially with $0.9 \% \mathrm{NaCl}$ and $4 \%$ PFA in $0.1 \mathrm{M} \mathrm{PB}$. Coronal brain slices at $150 \mu \mathrm{m}$ thickness were prepared by a microslicer (Dosaka). To label fine structure of neurons (Gan et al., 2000; Mataga et al., 2004), tungsten particles coated with lipophilic dye (DiI; Life Technologies) were delivered to the brain slices using the Helios Gene Gun (Bio-Rad). A confocal microscope (FluoView; Olympus) was used to image secondary apical dendrites of typical pyramidal neurons at the hippocampal area CA1. Dendritic protrusions were counted in $z$-stacks with NIH ImageJ.

Electrophysiology. Mice were deeply anesthetized with halothane (Takeda) and killed by decapitation. The whole brain was quickly removed into an ice-cold cutting solution containing the following (in $\mathrm{mm}$ ): 200 sucrose, 4 $\mathrm{KCl}, 1 \mathrm{NaH}_{2} \mathrm{PO}_{4}, 0.2 \mathrm{CaCl}_{2}, 10 \mathrm{MgCl}_{2}, 26.2$ $\mathrm{NaHCO}_{3}, 11 \mathrm{D}-(+)$-glucose, $0.1 \mathrm{~L}(+)$-ascorbic acid, and 0.5 sodium pyruvate, saturated with $95 \% \mathrm{O}_{2}$ and $5 \% \mathrm{CO}_{2}$. Each brain hemisphere glued on a piece of agar block ( $4 \%$ in saline) was sliced along the longer axis of hippocampus at a thickness of $400 \mu \mathrm{m}$, using a microslicer (LinearSlicer Pro7; DOSAKA). Hippocampi were dissected out of whole-brain slices and recovered in a submerged holding chamber containing a physiologic medium (aCSF) containing the following (in mM): $119 \mathrm{NaCl}, 2.5 \mathrm{KCl}$, $1 \mathrm{NaH}_{2} \mathrm{PO}_{4}, 2.5 \mathrm{CaCl}_{2}, 1.3 \mathrm{MgCl}_{2}, 26.2$ $\mathrm{NaHCO}_{3}, 11 \mathrm{D}-(+)$-glucose, $0.1 \mathrm{~L}(+)$-ascorbic acid, and 0.5 sodium pyruvate, continuously bubbled with $95 \% \mathrm{O}_{2}$ and $5 \% \mathrm{CO}_{2}$. The slices, which had been equilibrated for $>2 \mathrm{~h}$, were transferred to an immersion-type recording chamber and superfused with well bubbled aCSF at a rate of $2.5 \mathrm{ml} / \mathrm{min}$. All physiologic experiments were performed at $25^{\circ} \mathrm{C}$. Extracellular field potential recordings were performed using borosilicate glass electrodes filled with $3 \mathrm{M} \mathrm{NaCl}$ to obtain a low pipette resistance, resulting in high signal-to-noise ratio. Excitatory synaptic potentials were evoked with tungsten bipolar stimulating electrodes (WPI), which were connected to an isolated box (ISOFlex; A.M.P.I.) delivering constant voltage pulses of $200 \mu$ s duration to input fibers. External recording solutions contained the following (in $\mu \mathrm{M}$ ): 100 picrotoxin and 1 CGP55845 to block $\mathrm{GABA}_{\mathrm{A}}$ and $\mathrm{GABA}_{\mathrm{B}}$ receptors, respectively. CA3-CA1 fibers were surgically disconnected to prevent emergence of 
A
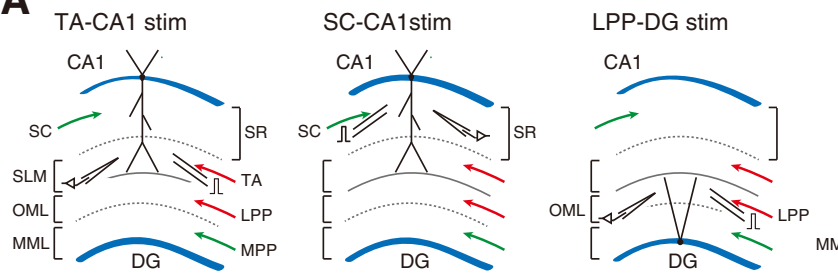

MPP-DG stim

B
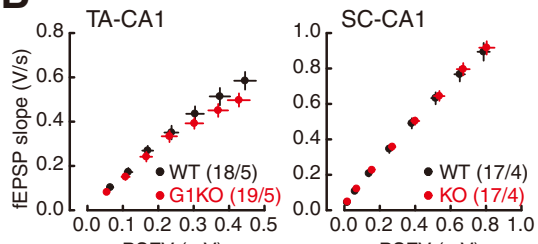

PSFV $(\mathrm{mV})$

$\operatorname{PSFV}(\mathrm{mV})$

\section{C}
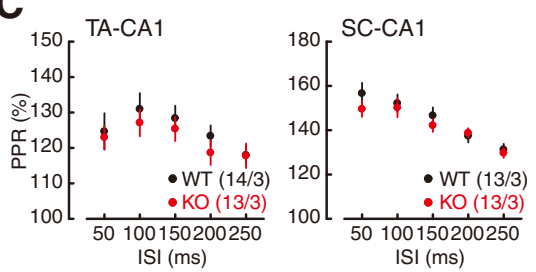

D
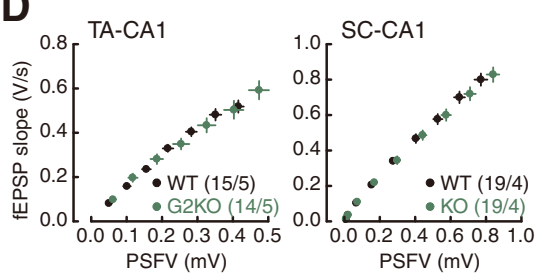

\section{$E$}

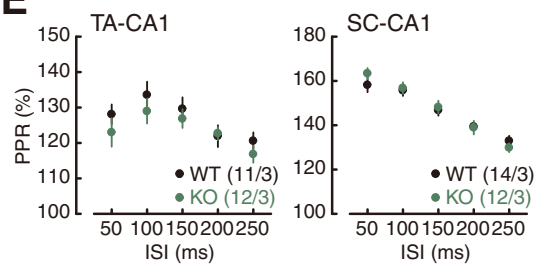

F
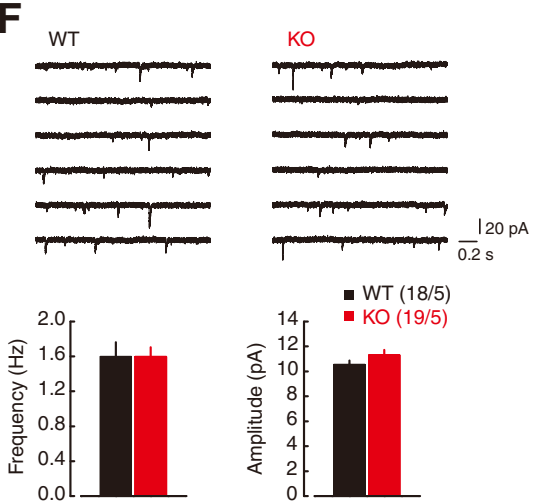
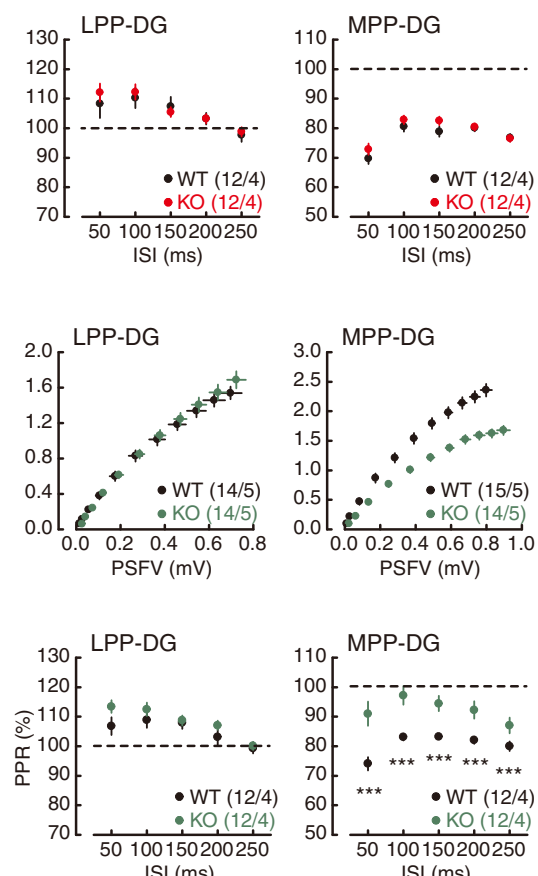

G
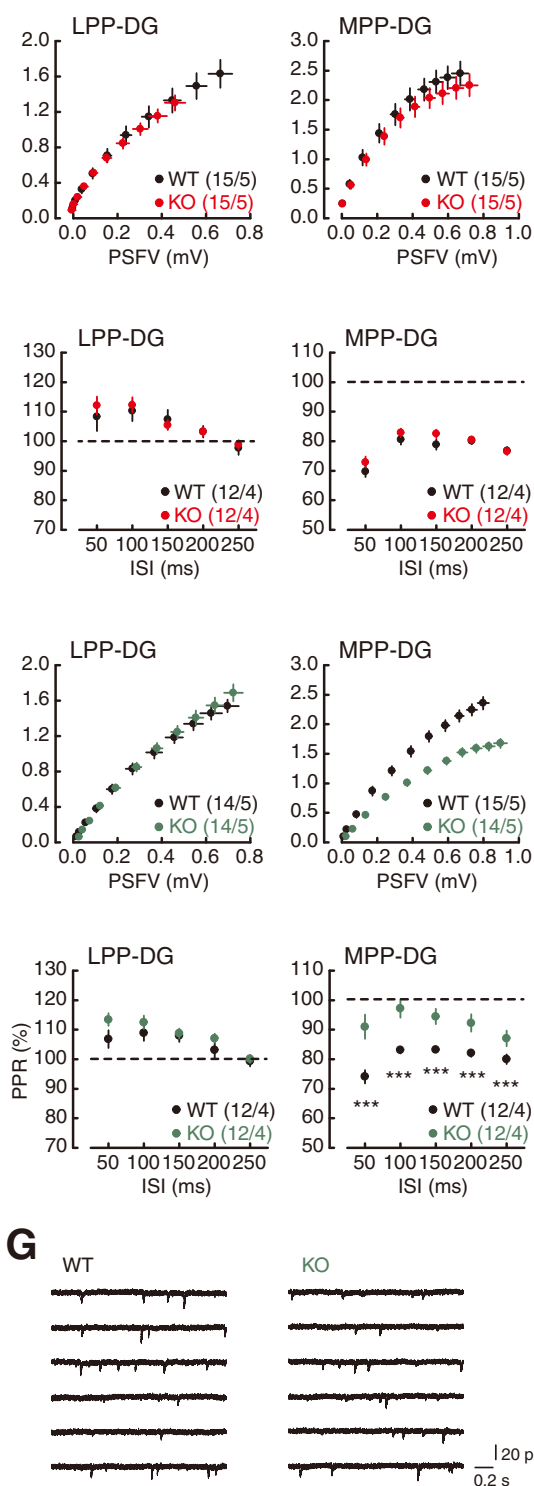

PSFV $(\mathrm{mV})$

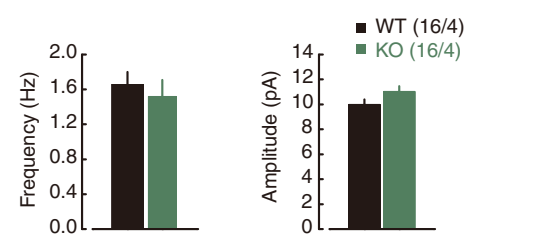

Figure 2. Deficiency of netrin-G2 attenuated synaptic transmission in the specific pathway. $A$, Schematics of field recording. Basal synaptic properties were examined in hippocampal CA1 and DG synapses. AMPAR-mediated fEPSPs were recorded by stimulating axon fibers: TA, SC, LPP, and MPP. Recording and bipolar stimulating electrodes were placed in the middle of each layer. $\boldsymbol{B}$, Relative postsynaptic responsiveness to presynaptic activity was not significantly different between netrin-G1-K0 and WT control mice. The average slopes of fEPSPs (10 consecutive recordings) were plotted as a function of the average amplitude of PSFV. C, The paired-pulse ratio (PPR; percentage) was not statistically different between netrin-G1-K0 and WT mice. The slope ratios were obtained by average fEPSPs (10 consecutive recordings) and plotted as a function of the interstimulus interval (ISI). D, Basal

CA3 epileptic recurrent surge under the disinhibited condition. In extracellular field recordings, the test field potentials were evoked at 0.1 $\mathrm{Hz}$ for Schaffer collateral (SC)-CA1 and lateral perforant path (LPP)-DG synapses and at 0.05 $\mathrm{Hz}$ for temporoammonic path (TA)-CA1 and medial perforant path (MPP)-DG synapses. For input-output test, only when SC fibers were stimulated, external solution additionally included a low concentration of CNQX $(1 \mu \mathrm{M})$ to partially block AMPA receptormediated fEPSPs, because SC-CA1 field responses usually showed much smaller presynaptic activity in regard to fEPSP and nonlinear development of fEPSPs as stimulus intensity increased, compared with other pathways. The incubation of the slices with CNQX $(1 \mu \mathrm{M})$ resulted in inhibition of $\sim 80 \%$ and helped to avoid the nonlinear increment of SCCA1 fEPSPs (Shimuta et al., 2001). As an exception, the input-output test for SC-CA1 of NGL2-KO mice was performed without CNQX. The examinations for input-output relations and short-term synaptic plasticity including paired-pulse facilitation/depression (PPF/ $\mathrm{PPD})$, post-tetanic potentiation (PTP), and posttheta burst potentiation $(\mathrm{PTBuP})$ were performed in the presence of D-AP5 $(25 \mu \mathrm{M}$ or 50 $\mu \mathrm{M})$. To induce PTP, a single tetanic train (100 $\mathrm{Hz}, 1 \mathrm{~s}$ ) was given to SC or TA. For LTP recordings of TA-CA1 and SC-CA1 synapses, different TBuS protocols were used to obtain reliable potentiation. TA-CA1 synapses were conditioned with four TBuS trains at $20 \mathrm{~s}$ intervals after making a $50 \mathrm{~min}$ baseline. Each TBuS consisted of five bursts at $5 \mathrm{~Hz}$, each of which has eight stimuli at $100 \mathrm{~Hz}$. Note that stimulus duration was doubled into $400 \mu$ s when TACA1 synapses were conditioned. For the induction of LTP at SC-CA1 synapses, a single TBS train (three bursts at $5 \mathrm{~Hz}$, each of which has four stimuli at $100 \mathrm{~Hz}$ ) was given to SC. The same patterns of TBuS were used to induce PTBuP. Synaptic transmission was pharmacologically potentiated by bath application of PDBu or forskolin/IBMX. Slope of the fEPSP was analyzed for the comparison between genotypes.

Whole-cell voltage-clamp configuration was obtained by a blind access with a patch pipette (3.5-8 M $\Omega$ ). The composition of the pipette solution contained the following (in $\mathrm{mm}$ ):

\footnotetext{
synaptic transmission was significantly reduced only at MPP-DG synapses, but normal at the SC-CA1 synapses of netrin-G2-KO mice. E, MPP-DG synapses of netrin-G2-K0 mice showed significantly increased PPR at all interstimulus intervals, while the SC-CA1 synapses showed comparable PPR to WT mice. Absence of netrin-G1 or netrin-G2 did not affect the basal synaptic properties of the neighboring pathways. $\boldsymbol{F}, \mathbf{G}$, Representative sample traces of mEPSC events recorded from DG granule cells of netrin-G1-KO $(\boldsymbol{F})$ and netrin-G2-KO (G) slices. No significant differences were observed in frequency and amplitude. The numbers of slices/granule neurons (left) and mice (right) used in each experiment are shown in parentheses. All bar graphs are represented as mean \pm SEM. Student's $t$ test, ${ }^{* * *} P<0.001$.
} 
A

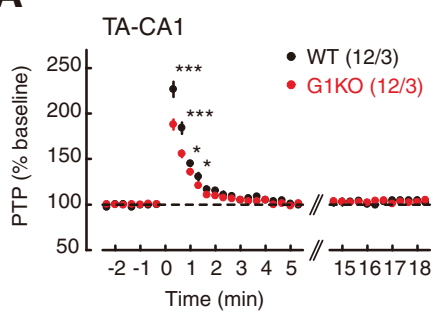

C

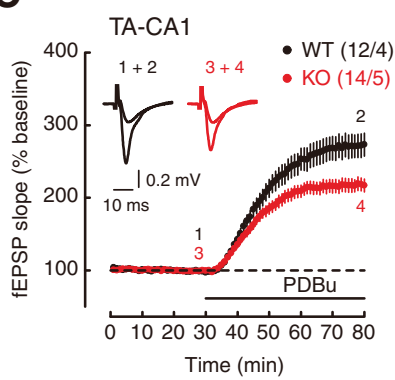

E

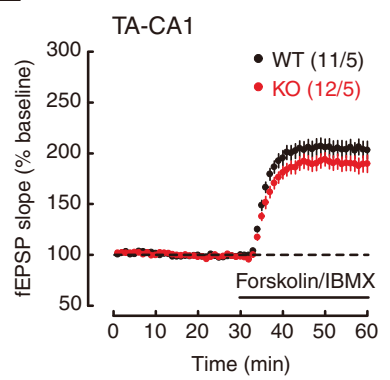

B

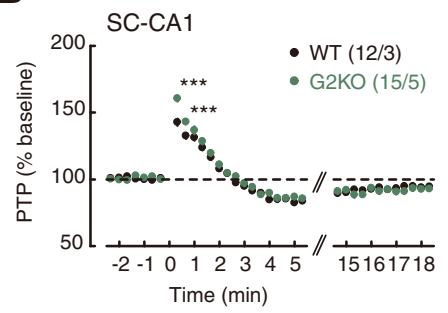

D

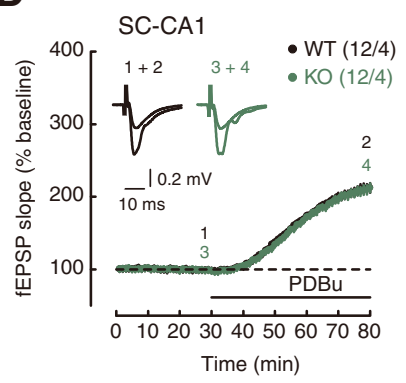

F

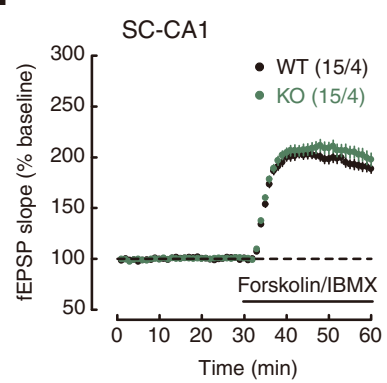

G

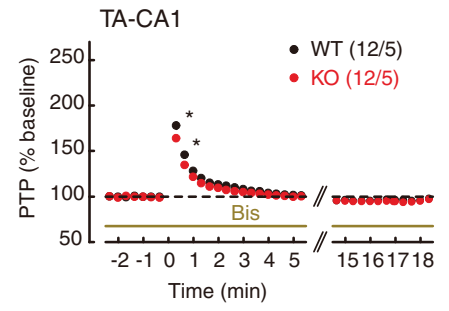

I

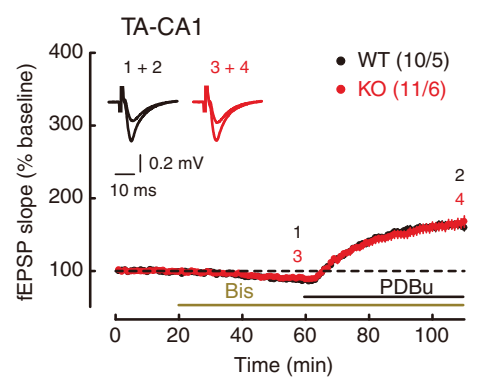

K

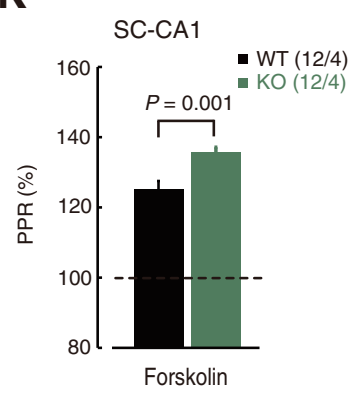

H

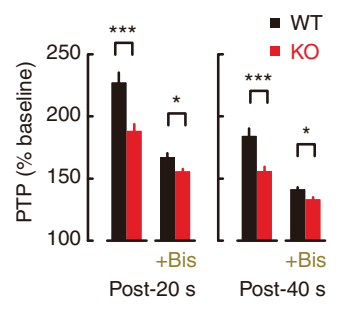

J

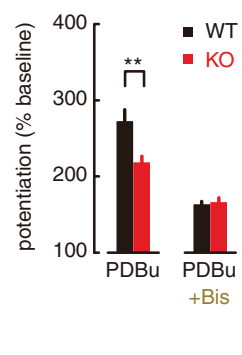

Figure 3. Altered PTP in netrin-G1-KO and netrin-G2-KO caused by distinct signaling deficits. A, B, PTP at the TA-CA1 synapses was impaired in netrin-G1-KO. In contrast, PTP at the SC-CA1 synapses was facilitated in netrin-G2-KO SC-CA1. C, D, fEPSP potentiation by PDBu $(0.4 \mu \mathrm{M})$ was reduced at TA-CA1 synapses in netrin-G1-K0, but normal at SC-CA1 synapses in netrin-G2-K0. The slope of fEPSP was normalized to the average value before the onset of PDBu application. Insets show superimposed average traces (during 2 min) before and after the treatment at the times indicated by the numbers. The average of potentiation during the last 5 min of recording was statistically compared between genotypes (WT vs netrin-G1-K0, ${ }^{* *} p<0.005$; WT vs netrin-G2-K0, $p=$ 0.86). $\boldsymbol{E}, \boldsymbol{F}$, fEPSP potentiation induced by combination of forskolin $(20 \mu \mathrm{M})$ and IBMX $(50 \mu \mathrm{m})$ was not statistically different between netrin-G mutant and WT mice (the average of potentiation during the last 5 min of recording; WT vs netrin-G1-K0, $p=0.19$; WT vs netrin-G2-KO, $p=0.16)$. G, Treatment of slices with PKC inhibitor, Bis (2 $\mu \mathrm{m})$ attenuated PTP generation in both WT and netrin-G1-KO mice. $\boldsymbol{H}$, Comparison of TA-CA1 PTP magnitudes at 20 and $40 \mathrm{~s}$ (left and right, respectively), following tetanic stimulation in the absence or presence of Bis. Values of bar graphs were extracted from $A$ and $\mathbf{G} . \mathbf{I}$, fEPSP potentiation by PDBu was indistinguishable in the presence of Bis between netrin-G1-K0 and WT (the average of potentiation during the last 5 min of recording; $P=$ 0.80). Insets show superimposed average traces (during $2 \mathrm{~min}$ ) before and after the treatment at the times indicated by the numbers. J, Comparison of the PDBu-induced synaptic potentiation in the absence (left) and presence (right) of Bis. Values are averages of the last 5 min of recording in $\mathbf{C}$ and $\boldsymbol{I}$. $\boldsymbol{K}$, After forskolin treatment, SC-CA1 synapses showed significantly greater (PPR) at $50 \mathrm{~ms}$ ISI in netrin-G2-K0, compared with WT control mice. L, In contrast, forskolin abolished PPD phenotype at MPP-DG synapses of netrin-G2-K0. fEPSPs were recorded at the indicated pathway shown above each part. Slices were treated with drug(s) as indicated by the solid line in each experiment. The numbers of slices (left) and mice (right) used in each experiment are shown in parentheses. Data are shown as mean \pm SEM. Student's $t$ test; ${ }^{*} P<0.05$, ${ }^{* *} P<0.01$, ${ }^{* * *} P<0.001$, and absolute $P$ values.

122.5 Cs gluconate, $17.5 \mathrm{CsCl}, 10 \mathrm{HEPES}, 0.2 \mathrm{EGTA}, 8 \mathrm{NaCl}, 2 \mathrm{Mg}$-ATP, $0.3 \mathrm{Na} 3-\mathrm{GTP}$, and 5 QX-314, pH 7.3, 290-300 mOsm. Miniature EPSCs were recorded from DG granule cells in the presence of picrotoxin (100 $\mu \mathrm{M})$, CGP55845 $(1 \mu \mathrm{M})$, and tetrodotoxin $(1 \mu \mathrm{M})$, at $-80 \mathrm{mV}$. AMPA receptor and NMDA receptor currents (AMPAR-EPSC and NMDAREPSC) were recorded at $-70 \mathrm{mV}$ and $+50 \mathrm{mV} /-20 \mathrm{mV}$, respectively. NMDAR-EPSCs were recorded after pharmacologic isolation with NBQX $(20 \mu \mathrm{M})$. It should be noted that NMDAR-EPSC was evaluated by depolarizing membrane potential at $-20 \mathrm{mV}$, not more positive potential, when a TA pathway was stimulated, because TA-evoked NMDAREPSC exhibits inward rectification, as previously reported (Otmakhova et al., 2002). Also, in our slice experimental conditions, the absolute amount of NMDAR-EPSC at $-20 \mathrm{mV}$ was equivalent to or usually greater than that recorded at $+50 \mathrm{mV}$ at TA-CA1 synapses (data not shown). Amplitude of the EPSC was analyzed for the comparison between genotypes. Series resistances were $<30 \mathrm{M} \Omega$ and there was no significant difference in series resistance between experimental groups. The monitored synaptic responses were filtered at $1-2 \mathrm{kHz}$ using Axon
200B and digitized at $10 \mathrm{kHz}$ using Clampex software of pClamp 9 suite (Molecular Devices). Membrane potentials in whole-cell patch were represented without being compensated for liquid junction potential.

Drugs were purchased from the following sources: picrotoxin, forskolin, tetrodotoxin, and IBMX from Nacalai Tesque; CGP55845, D- AP5, CNQX, and NBQX from Tocris Bioscience; QX-314 and PDBu from Sigma; and bisindolylmaleimide I (Bis) from Calbiochem.

Immunoblot analysis. Fresh forebrains were homogenized in 10 volumes of ice-cold HEPES-buffered sucrose solution containing the following (in $\mathrm{mm}$ ): 320 sucrose, 5 HEPES, pH 7.4, containing protease inhibitor cocktail (Roche). After centrifuging the homogenate at $1400 \times$ $g$, crude membrane (P2) fraction was pelleted by further centrifuging the supernatant $(\mathrm{S} 1)$ at $12,000 \times g$. The pellet was suspended and lysed with $6 \mathrm{~mm}$ Tris buffer, $\mathrm{pH} 8$, on ice for $30 \mathrm{~min}$. The lysate was again pelleted at $25,000 \times g$ and resuspended with HEPES-buffered sucrose solution; synaptic plasma membrane (SPM) was fractionated with layered sucrose gradient $(0.8 \mathrm{~m} / 1.0 \mathrm{~m} / 1.2 \mathrm{~m}$ sucrose plus $5 \mathrm{~mm}$ HEPES $)$ at $82,700 \times \mathrm{g}$. Interface between $1.0 \mathrm{M}$ and $1.2 \mathrm{M}$ sucrose was retrieved. Proteins of P2 
(25 $\mu \mathrm{g})$ and SPM $(15 \mu \mathrm{g})$ fractions were separated by SDS-PAGE (10\%), then transferred onto PVDF membrane (Immobilon; Millipore). After blocking in TBST containing 5\% skim milk, the blot membrane was incubated at $4^{\circ} \mathrm{C}$ with rabbit primary antibodies at appropriate dilution as follows (P2/SPM): antinetrin-G1 (1:1000/1:2000) and anti-netrin-G2 (1:200/1:500). For normalizing protein amounts, anti-actin (Millipore) or anti-GAPDH (Ambion) antibodies were used.

Statistics. All values are expressed as mean \pm SEM. The data were analyzed by the one-way ANOVA and Student's two-tailed $t$ test with IBM SPSS Statistics (version 21).

\section{Results}

\section{Synaptic localization of netrin-Gs and NGLs}

Immunohistochemical findings at the light microscopic level indicate that netrin-G1 and netrin-G2 distribute along distinct axons, and their receptors, NGL1 and NGL2, are concentrated on subdendritic segments in a layerselective manner (Nishimura-Akiyoshi et al., 2007). However, subcellular localizations of netrin-Gs and NGLs in vivo remain obscure. We examined their localization using subtype-specific antibodies for these molecules. In the hippocampal CA1 and DG, the distal layer [SLM and outer molecular layer (OML)] and proximal/middle layer [SR and middle molecular layer (MML)] were clearly distinguished by immunoreactivity for netrin-G1 and netrin-G2, respectively, representing distinct inputs to CA1 pyramidal and DG granule cells (Fig. $1 A, B$ ). Confocal microscopic analysis showed close localization of netrin-G1 and a presynaptic marker Bassoon in the OML (Fig. 1C). The subcellular distributions of netrin-G and NGL proteins in the hippocampus were further examined by post-embedding iEM. Excitatory asymmetric synapses immunolabeled with netrin-G1 and netrin-G2 antibodies were detected in the SLM and SR, respectively (Fig. 1D), and immunosignals for NGL1 and NGL2 were detected along PSDs of the SLM and SR, respectively (Fig. $1 E$ ). The specificity of the antibodies used in the post-embedding preparation was assessed by counting synapses with one or more immunogold particles in a given observation area between WT and KO ultrathin sections, and between the distinct layers of WT samples (Fig. 7C,D; data not shown). The location of immunoparticles at synapses was determined by measuring the radial distance of each gold particle in relation to the presynaptic membrane. Netrin-G1 and netrin-G2 immunoparticles had peak radial distances within the first external bin from the presynaptic membrane (i.e., within the synaptic cleft), while the fre-
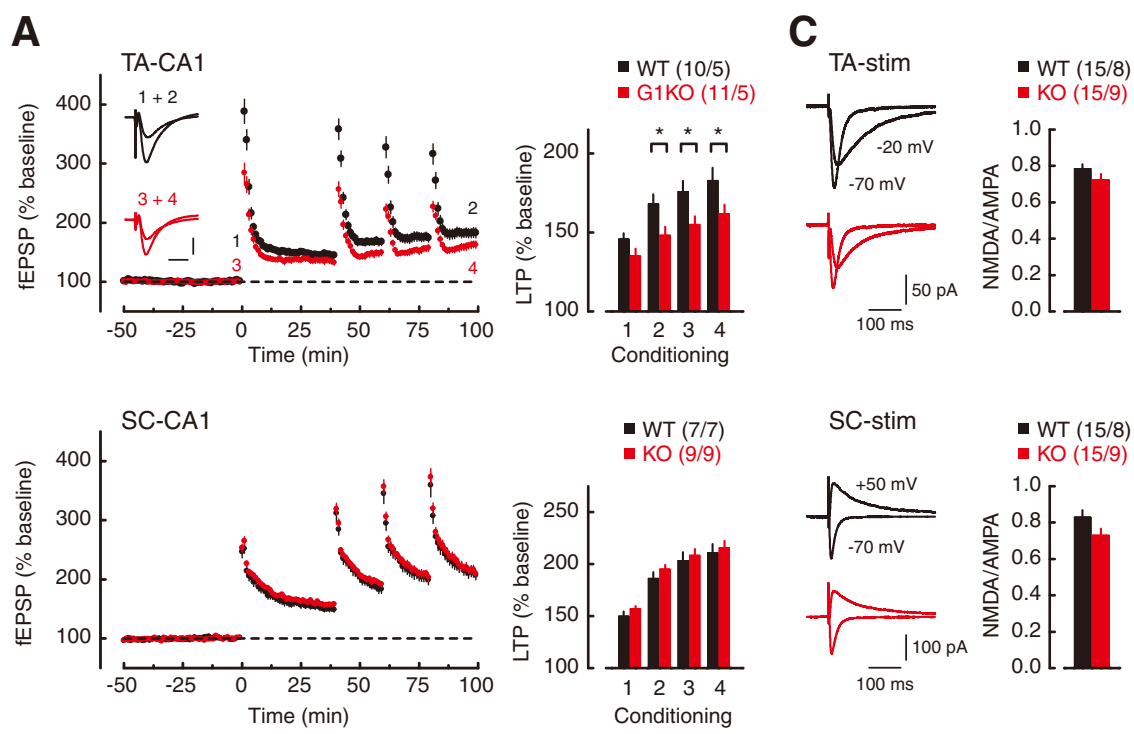

B
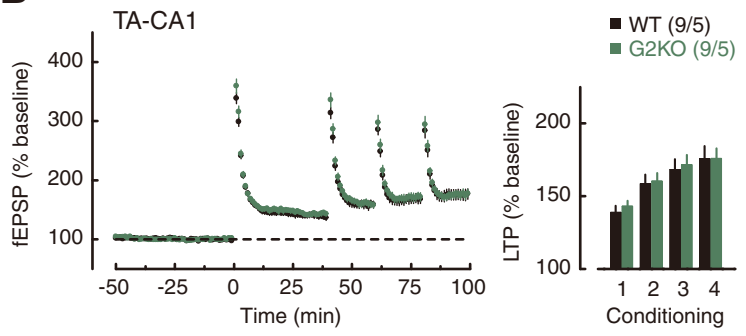

D
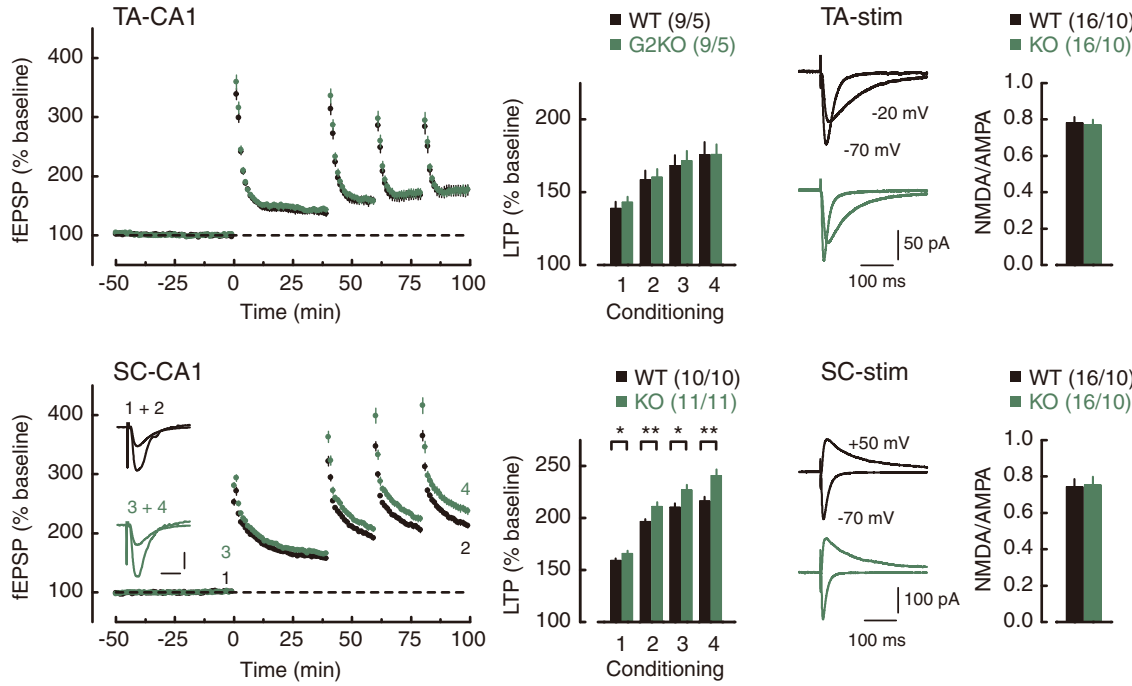

Figure 4. Altered hippocampal LTP in netrin-G-KO mice. $\boldsymbol{A}$, TBuS-induced LTP at the TA-CA1 synapses was attenuated in netrin-G1-KO (top). The slope of fEPSP was normalized to the average value during the 50 min before the initial TBuS. TA-CA1 synapses were electrically conditioned four times with TBuS at 0, 40,60, and $80 \mathrm{~min}$. Insets show superimposed average traces (10 consecutive fEPSPS) before TBuS and in the last $5 \mathrm{~min}$ of each recording, as indicated by the numbers. Absence of netrin-G1 from SLM did not affect LTP capability at proximal neighboring SC-CA1 synapses (bottom). Bar graphs show a comparison of the graded increase of LTP with the number of TBuSs between netrin-G1-K0 and WT mice. Calibration: $0.2 \mathrm{mV}, 10 \mathrm{~ms}$. $\boldsymbol{B}$, TBuS-induced LTP at SC-CA1 synapses was increased in netrin-G2-KO mice (bottom). Conditioning timing was the same as $\boldsymbol{A}$. Insets show superimposed average traces of the $5 \mathrm{~min}$ before the initial TBuS and in the last $5 \mathrm{~min}$ of each recording, as indicated by the numbers. Absence of netrin-G2 from SR did not affect LTP capability at distal neighboring TA-CA1 synapses (top). Bar graphs show a comparison of the graded increase of LTP with the number of TBuSs between netrin-G2-KO and WT mice. Calibration: $0.2 \mathrm{mV}, 10 \mathrm{~ms}$. C, D, AMPARESPCs and NMDAR-EPSCS were recorded from CA1 pyramidal neurons. Superimposed traces are representative average traces (10 consecutive responses) of AMPAR-EPSC recorded at $-70 \mathrm{mV}$ and NMDAR-EPSC at $-20 \mathrm{mV}$ (for TA-stimulation, top) or at $+50 \mathrm{mV}$ (for SC-stimulation, bottom). The amplitude ratio (NMDA/AMPA) was not statistically different between K0 and WT mice. Numbers of slices/pyramidal neurons (left) and mice (right) used in each experiment are shown in parentheses. Data are shown as mean \pm SEM. Student's $t$ test, ${ }^{*} P<0.05$, and ${ }^{* *} P<0.01$.

quency of NGL1 labeling was highest in the postsynaptic face (Fig. $1 F$ ). The data for NGL2 were excluded from this analysis, because of its modest signal-to-noise ratio in the post-embedding experiments. The pre-embedding iEM revealed distribution of netrin-G1 along the axon (Fig. $1 G$ ). These findings indicate that netrin-Gs are presynaptic proteins and NGLs are postsynaptic proteins. 
A

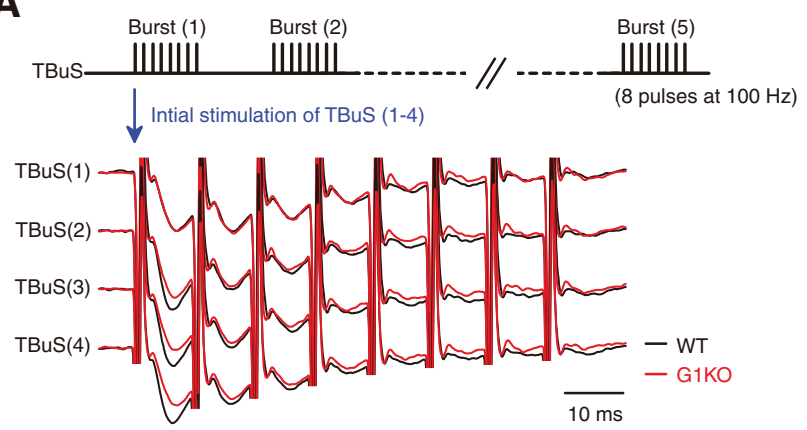

B
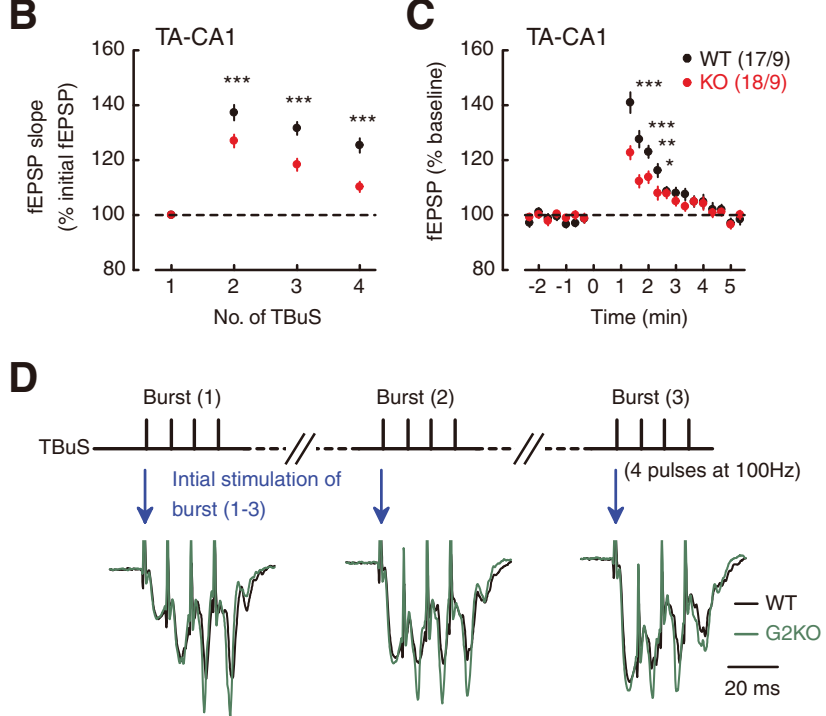

E

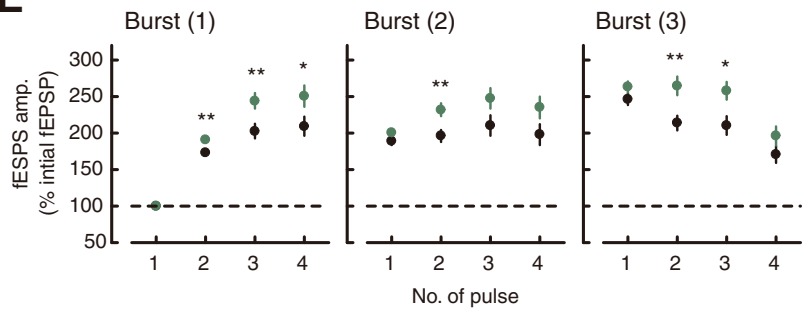

$\mathbf{F}$

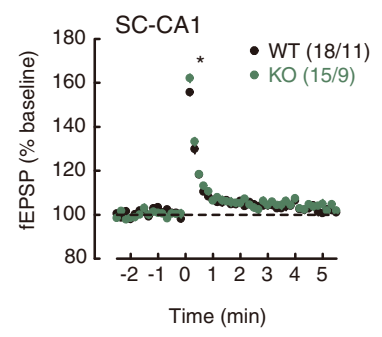

Figure 5. Impaired short-term plasticity induced by TBuS in netrin-Gs-KO mice. $A$, TBuS train used for TA-CA1 LTP induction. Each TBuS composes five bursts $(1-5,5 \mathrm{~Hz})$ of eight pulses (100 $\mathrm{Hz}$ ). Development of TA-CA1 fEPSP by the consecutive four trains of TBuS (1-4), in the presence of D-AP5 $(50 \mu \mathrm{M})$, was impaired in netrin-G1-K0, compared with the WT mice. Superimposed are representative TA-CA1 fEPSPs traces during the burst (1) of each TBuS (blue arrow), scaling with the peak amplitude of fEPSP evoked by initial stimulus of TBuS (1). B , Relative slope of TA-CA1 fEPSP in multiple TBuS conditionings in $\boldsymbol{A}$ was plotted with the number of TBuS. $\boldsymbol{C}$, Synaptic potentiation following consecutive four TBuS trains (PTBuP) was decreased in netrinG1-K0, compared with WT mice. D, TBuS train used for SC-CA1 LTP induction, which composes three bursts $(1-3,5 \mathrm{~Hz})$ of four pulses $(100 \mathrm{~Hz})$. Superimposed are representative fEPSP traces elicited by three bursts (1-3) in the presence of D-AP5 $(50 \mu \mathrm{M})$, scaling with the peak amplitude of fEPSP evoked by initial stimulus of burst (1). Intraburst synaptic facilitation was aberrantly

\section{Netrin-G supports synaptic transmission at complementary pathways}

To determine whether the lack of netrin-G leads to structurally abnormal synapses, synapse density and size were analyzed in CA1 subregions, the SLM and SR, of netrin-G1-KO and netrinG2-KO mice by conventional transmission EM. The differences in these parameters among adult WT, netrin-G1-KO, and netrinG2-KO mice were not significant [SR synapse density (average \pm $\mathrm{SEM}) / \mu \mathrm{m}^{2}$ : WT, $0.94 \pm 0.04$; G1-KO, $0.95 \pm 0.04$; G2-KO, $1.03 \pm 0.04 ; F_{(2,216)}=1.345, p=0.263$, one-way ANOVA; SLM synapse density $/ \mu \mathrm{m}^{2}$ : WT, $0.60 \pm 0.04$; G1-KO, $0.56 \pm 0.03$; $\mathrm{G} 2-\mathrm{KO}, 0.63 \pm 0.04 ; F_{(2,199)}=0.931, p=0.492$; SR synapse size (width, $\mu \mathrm{m}$ ): WT, 192.0 \pm 2.87 ; G1-KO, $198.9 \pm 3.41$; G2-KO, $200.1 \pm 2.91: F_{(2,1395)}=2.091, p=0.124$; SLM synapse size: $\mathrm{WT}$, $229.3 \pm 4.6$; G1-KO, $238.8 \pm 6.4 ; \mathrm{G} 2-\mathrm{KO}, 235.6 \pm 5.8: F_{(2,792)}=$ $0.683, p=0.506]$.

To investigate the functional consequence of disrupted netrin-G/NGL interactions at synapses, we first examined synaptic transmission of hippocampal circuits in netrin-G-KO mice. AMPAR-mediated fEPSPs were recorded in the hippocampal CA1 and DG upon stimulation of SC/TA and MPP/LPP pathways, respectively (Fig. $2 A$ ). In the netrin-G1-KO, the relation between the presynaptic fiber volley activity (PSFV) and fEPSP was not altered at all synapses tested (Fig. 2B). Furthermore, synaptic facilitation in response to paired-pulse stimuli, which is inversely correlated with release probability (Zucker and Regehr, 2002), was not significantly distinguishable between genotypes (Fig. 2C). Netrin-G2 deficiency affected basal synaptic transmission in a pathway-specific manner. Basal synaptic transmission was significantly reduced at MPP-DG synapses, whereas it was normal at other synapses (Fig. 2D). PPD was also attenuated specifically at MPP-DG synapses in netrin-G2-KO mice (Fig. 2E), suggesting impaired release probability. The frequency and amplitude of the mEPSCs, from DG granule cells, however, did not differ between the netrin-Gs mutants and control WT mice (Fig. $2 F, G$ ), suggesting a significant role of netrin-G2 on evoked vesicular release. Loss of the netrin-G1 or netrin-G2 subtype in one pathway did not affect the basal synaptic properties at the neighboring netrin-G1-negative or netrin-G2-negative hippocampal circuits.

\section{Presynaptic plasticity is differentially regulated by netrin-G1 and netrin-G2 complexes}

We wondered if presynaptic deficits in netrin-Gs-KO might manifest under physiologically challenging paradigms in the TACA1 and SC-CA1 circuits that showed no abnormalities in basal synaptic transmission. We induced synaptic plasticity and investigated PTP under the presence of NMDAR antagonist, which is a mostly presynapse-dependent short-term plasticity (Zucker and Regehr, 2002; Fioravante et al., 2011). PTP induction was attenuated at TA-CA1 synapses of netrin-G1-KO and facilitated at SC-CA1 synapses of netrin-G2-KO mice (Fig. $3 A, B$ ). Pharmacologic evidence suggests that PTP is largely mediated by the activation of presynaptic PKC induced by repetitive synaptic firing. Bath application of phorbol ester potentiates evoked transmitter

$\leftarrow$

enhanced in netrin-G2-KO, when compared with WT mice. $E$, Relative amplitude of SC-CA1 fEPSP during each burst in $\boldsymbol{D}$ was plotted with the number of stimulus pulse (1-4).F, PTBuP was slightly but significantly enhanced in netrin-G2-KO, compared with WT mice. The numbers of slices (left) and mice (right) used in each experiment are shown in parentheses. Data are represented as mean \pm SEM. Student's $t$ test, ${ }^{*} P<0.05,{ }^{* *} P<0.01,{ }^{* * *} P<0.001$. 
release at many synapses (Malenka et al., 1986; Shapira et al., 1987; Hori et al., 1999; Lou et al., 2005; Korogod et al., 2007; Wierda et al., 2007; Lou et al., 2008) and occludes PTP generation (Korogod et al., 2007), and PKC antagonists diminish PTP (Brager et al., 2003; Beierlein et al., 2007; Korogod et al., 2007; Lee et al., 2007). Therefore, we investigated the enhancing effect of a phorbol ester derivative, $\mathrm{PDBu}$, which activates $\mathrm{PKC}$ as well as presynaptic active-zone protein Munc-13s (Hori et al., 1999; Lou et al., 2008), toward TACA1 and SC-CA1 synaptic responses, to examine whether the differentially impaired PTP observed in netrin-G1-KO and netrin-G2-KO mice was due to the disruption of an intrinsic signaling pathway through PKC. Both TA-CA1 and SCCA1 fEPSPs gradually increased upon $\mathrm{PDBu}(0.4 \mu \mathrm{M})$ application. Synaptic responsiveness to the drug was significantly impaired at netrin-G1-KO TA-CA1 synapses (Fig. 3C), but unaltered at netrinG2-KO SC-CA1 synapses (Fig. 3D). We next examined the effect of a combination of forskolin $(20 \mu \mathrm{M})$ and IBMX $(50 \mu \mathrm{M})$, which promotes PKA and guanine nucleotide exchange factor directly activated by cAMP (cAMP-GEF, RapGEF, or Epac) signaling processes by raising intracellular cAMP levels, leading to enhanced neurotransmission (Chavez-Noriega and Stevens, 1994; Sakaba and Neher, 2001; Kaneko and Takahashi, 2004; Huang and Hsu, 2006). Chemical potentiation by forskolin/IBMX was not statistically distinguishable between netrin-G KO and WT mice (Fig. $3 E, F$ ). These findings indicate that netrin-G1 deficiency at TA-CA1 synapse selectively impairs the signaling pathway downstream of diacylglycerol, which bifurcates PKC-dependent (through phosphorylation by PKC) and PKC-independent (through diacylglycerol binding substrates such as Munc-13s) signaling components. Pre-incubation with a selective PKC inhibitor, bisindolylmaleimide I (Bis; $2 \mu \mathrm{M}$ ), diminished the difference in the magnitude of PTP at TA-CA1 synapses (Fig. $3 G, H$ ), and the $\mathrm{PDBu}$-dependent potentiation between netrin-G1-KO and WT mice (Fig. 3I,J). These findings suggest that intrinsic phosphorylation processes mediated by PKC are hampered or that the functionality of the PKC-targeted substrate is impaired at netrin-G1-deficient TA presynaptic terminals, whereas netrin-G2 is coupled to distinct signaling from PKC, in hippocampal CA1 circuits. Interestingly, forskolin treatment became phenotypic in the PPF at the netrin-G2-KO SC-CA1 synapses (Fig. $3 K$ ), while no differences were noted under naive conditions (Fig. 2E). Moreover, forskolin treatment abolished the PPD phenotype in netrin-G2-KO MPP-DG synapses (Fig. $3 L$ ). These findings suggest that netrin-G2 has a role in regulating presynaptic mechanisms involving cAMP. These findings suggest that both netrin-G subtypes are functionally involved in synaptic efficacy modulation induced by intense synaptic ac-
B
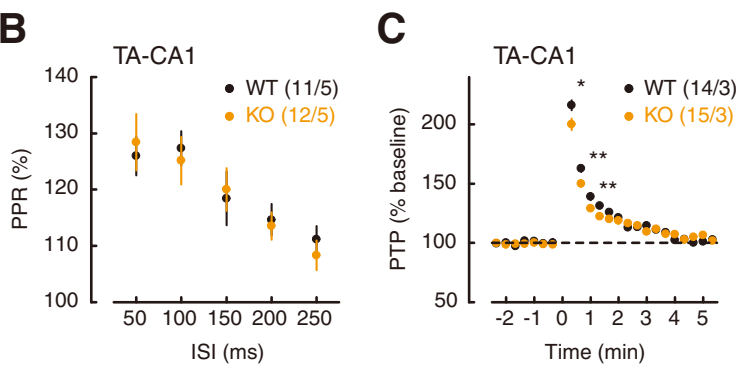

E
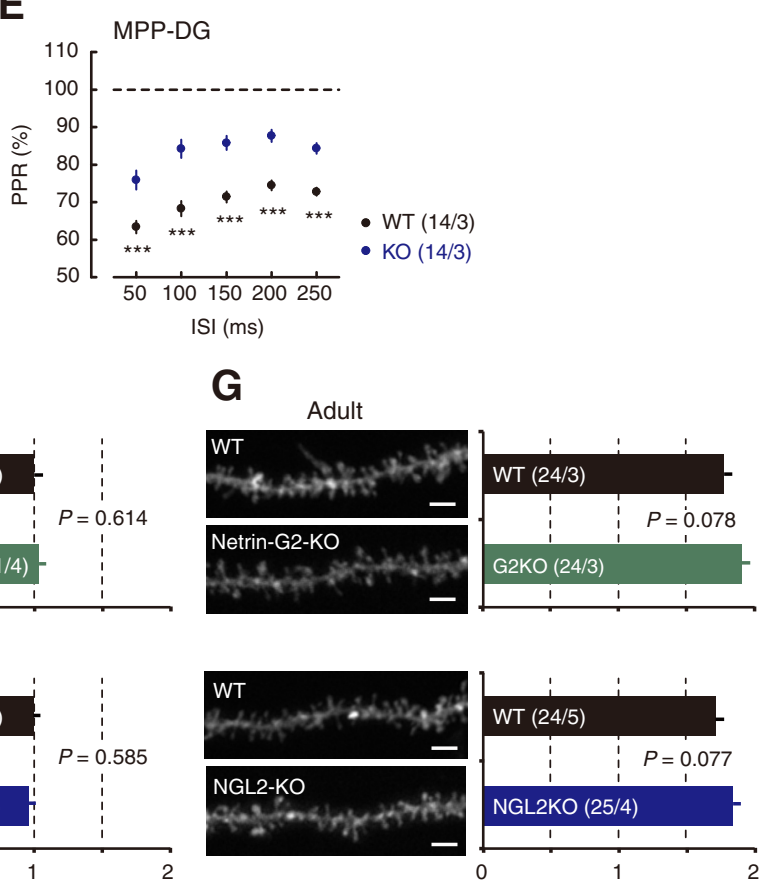

No. of protrusions $/ \mu \mathrm{m}$

Figure 6. Presynaptic abnormalities in NGL-KO mice and normal dendritic morphologies of netrin-G2-K0 and NGL2-KO mice. $A-C$, Synaptic phenotypes in TA-CA1 pathway of adult NGL1-KO mice. A, Normal basal synaptic transmission. $B$, Normal paired$\boldsymbol{A}-\boldsymbol{E}$. Numbers of dendritic segments (left) and mice (right) are shown in parentheses for $\boldsymbol{F}$ and $\boldsymbol{G}$. Data are shown as mean \pm SEM. Student's t test, shown are ${ }^{*} P<0.05,{ }^{* *} P<0.01,{ }^{* * *} P<0.001$ and absolute values.

tivities, such as high-frequency stimuli, although they are not necessarily required to maintain basal transmission in hippocampal CA1 circuits.

\section{Hippocampal LTP is differentially supported by netrin-G1 and netrin-G2 complexes}

We further analyzed LTP induced by TBuS in hippocampal CA1 circuits of netrin-G1-KO and netrin-G2-KO mice. LTP was induced in an NMDAR-dependent manner (Figs. $4 A, B, 5 C, F$ ), and the magnitudes were progressively increased by multiple conditionings in a stepwise manner (Fig. $4 A, B$ ). Although initial conditioning of the TA-CA1 synapse was insufficient to cause a significant difference in the magnitude of LTP, subsequently applied multiple conditionings revealed impaired LTP in netrinG1-KO mice (Fig. 4A, top). In contrast, SC-CA1 LTP was facilitated in netrin-G2-KO mice (Fig. $4 B$, bottom). The effects of $\mathrm{KO}$ on LTP were specific to the pathway where the protein was expressed. At the pathway where the protein was not expressed, LTP was intact (Fig. 4A, bottom; B, top). 
A
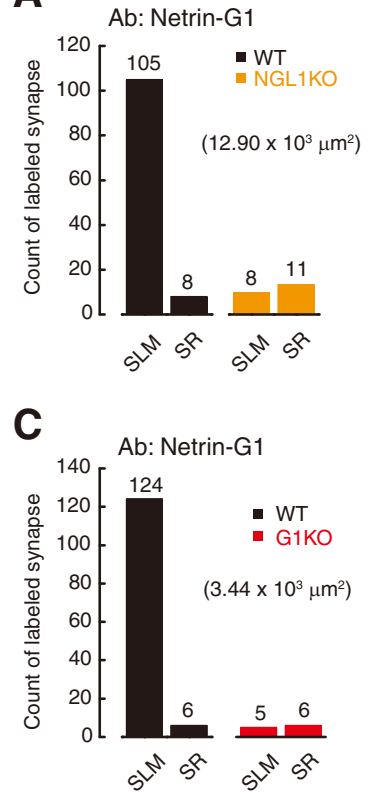

B

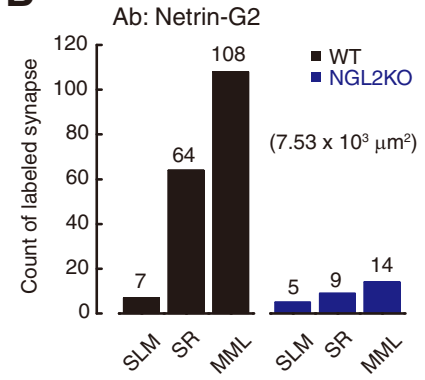

D

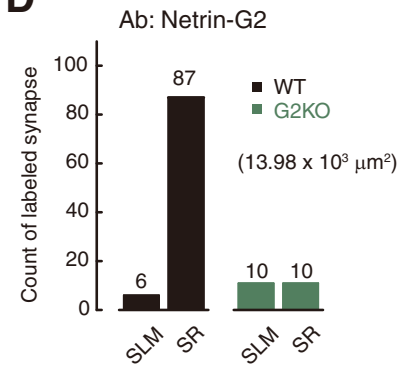

Figure 7. Disappearance of presynaptic netrin-Gs in NGL-KO mice. $\boldsymbol{A}, \boldsymbol{B}$, Subregional iEM analyses for netrin-Gs in NGL-KO mice. Ultrathin sections from NGL1-KO and NGL2-KO mice were immunoreacted with antibodies against netrin-G1 and netrin-G2, respectively. $C, D, S i m-$ ilar iEM analyses for netrin-Gs in netrin-G-KO mice revealed specificity of immune signals. Counts of synapses labeled with one or more immunogold(s) are shown on top of each bar. Searched area for each immunoreaction is shown in parentheses. Equivalent semiquantitative results were duplicated with blocks prepared from another set of WT and mutant mice (data not shown).

NGLs potentially interact with PSD proteins, including PSD95, PSD-93, SAP-102, and SAP-97, via C-terminal PDZ binding sequences, and NGL2 forms macrocomplexes with PSD-95 and NMDAR in the brain (Kim et al., 2006). The lack of netrin-G1 and netrin-G2 causes diffusion of NGL1 and NGL2 from a circuit-selective subdendritic segment to the entire dendrite in vivo (Nishimura-Akiyoshi et al., 2007). Thus, postsynaptic protein-protein network function, including NMDARs, might be involved in the LTP phenotypes. NMDAR activation is essential for LTP induction. We therefore examined whether postsynaptic NMDARs are functionally altered in mice lacking one of the netrin-Gs. Netrin-G deficiency, however, did not affect the amplitude ratio of NMDAR- and AMPAR-mediated EPSCs (Fig. $4 C, D$ ) or the charge transfer ratio (data not shown). Because the basal synaptic transmission mediated by AMPAR activation was indistinguishable in the hippocampal CA1 area between genotypes (Fig. $2 B, D$ ), it is unlikely that NMDAR functionality is impaired at synapses that are netrin-G deficient. Therefore, opposing LTP phenotypes, decreased or increased in netrin-G1-KO and netrin-G2-KO synapses, respectively, could not be attributed to NMDAR malfunction.

The fEPSPs just after the first TBuS conditioning were profoundly attenuated at the TA-CA1 synapses of netrin-G1-KO mice, and significantly potentiated at the SC-CA1 synapses of netrin-G2-KO mice, implying a presynaptic mechanism(s) underlying the LTP phenotypes. To test this possibility, we applied the same stimulation protocol for inducing LTP under the presence of NMDAR antagonist D-AP5 (Fig. $5 A, D$ ). As expected, the enhancement during the TBuS(s) was significantly attenuated at TA-CA1 synapses of netrin-G1-KO mice and facilitated at the SC-CA1 synapses of netrin-G2-KO mice (Fig. 5B,E), The

PTBuP, short-term potentiation after TBuS, was also attenuated at TA-CA1 synapses of netrin-G1-KO mice and facilitated at the SC-CA1 synapses of netrin-G2-KO mice (Fig. 5C,F). These results support the notion that the LTP phenotypes are at least in part due to functional consequences at the presynaptic site.

\section{Presynaptic short-term plasticity is regulated by NGLs similar to netrin-Gs}

The lack of netrin-G1 or netrin-G2 caused circuit-selective abnormalities in synaptic plasticity, such as attenuated PTP in the netrin-G1-KO TA-CA1 pathway and attenuated PPD in the netrin-G2-KO MMP-DG pathway. The synaptic abnormalities could be caused by disruption of the netrin-G/NGL interactions or loss of the cell-autonomous functions of netrin-Gs unrelated to the ligand/receptor interaction.

To gain insights into the alternative possibilities, we generated NGL1-KO and NGL2-KO mice and examined synaptic plasticity in these mice. We observed that PTP was attenuated at TA-CA1 synapses of adult NGL1-KO mice, while basal transmission and PPF were normal (Fig. 6A-C), similar to the phenotypes of adult netrin-G1-KO mice. In adult NGL2-KO mice, we observed normal basal synaptic transmission at the SC-CA1 synapses and attenuated PPD at MMP-DG synapses (Fig. 6D,E), similar to the phenotypes of netrin-G2-KO mice. These findings suggest that netrin-G/NGL interactions are required for the presynaptic function of netrin-G proteins.

DeNardo et al. (2012) observed attenuation of postsynaptic responses and a reduced density of dendritic spines of CA1 pyramidal neurons in juvenile NGL2-KO mice. We hypothesized that the differences between their studies and our studies could be due to the age difference of subjects analyzed or the strain difference. To test these hypotheses, we compared densities of spines on secondary dendrites of CA1 pyramidal neurons in the SR of netrin-G2-KO, NGL2-KO mice with their WT littermates at P14 and adults (7-9 months old). We observed no differences between genotypes at both ages (Fig. $6 F, G$ ), ruling out the former hypothesis. Genetic backgrounds of mice may in part underlie the differential phenotypes. Our netrin-G2-KO and NGL2-KO mice are C57BL6J congenic and isogenic strains, respectively. Their mice likely have mixed backgrounds.

\section{Synaptic localization of netrin-Gs is regulated by NGLs}

Our results thus far suggested that netrin-G/NGL interactions are required for the presynaptic function of netrin-G proteins. One possible mechanism is that localization of netrin-Gs within presynaptic membrane is regulated by postsynaptic NGLs at the synaptic cleft. To examine this possibility, we performed iEM with specific antibodies against netrin-G1 and netrin-G2 in hippocampal subregions of NGL1-KO and NGL2-KO mice. Compared with the frequency of synapses immunolabeled on WT ultrathin sections, those labeled with anti-netrin-G1 and antinetrin-G2 antibodies were negligible on NGL1-KO and NGL2-KO sections (Fig. 7). These findings suggest that postsynaptic NGLs are required to retain netrin-Gs on presynaptic membranes, which is a mechanistic explanation for the nearly identical presynaptic phenotypes between netrin-G-KO and NGL-KO mice.

To gain further insight into the netrin-G/NGL interaction in vivo, we quantified the amount of netrin-G attached to the plasma membrane (P2-netrin-G) and synaptically localized netrin-G (SPM-netrin-G) in NGL-KO mice. We previously demonstrated that a lack of netrin-G1 and netrin-G2 affects the distribution but not the amount of NGL1 and NGL2 (Nishimura-Akiyoshi et al., 2007). Interestingly, total amounts of 
P2-netrin-G1 were decreased in NGL1-KO mice (Fig. 8A). The reduction of SPM-netrin-G1 was more evident in NGL1-KO mice (Fig. 8B). Consistent with the biochemical data, immunohistochemical analysis revealed a markedly reduced intensity for netrin-G1 in NGL1-KO mice (Fig. 8C). Multiple netrin-G1 bands in the Western blot (WB) analysis represent isoforms generated by alternative splicing, and these isoforms are differentially expressed in distinct neuronal subsets (Nakashiba et al., 2000). The reduction rate of the netrin-G1 isoforms varied in P2 and SPM fractions. These results might suggest the presence of an isoform-selective mechanism for maintaining presynaptic netrin-G1. Similar to the case of NGL1-KO mice, WB analysis revealed clear reduction of netrin-G2 in $\mathrm{P} 2$ and SPM fractions of NGL2-KO mice (Fig. $8 D, E)$. The reduction rate was greater in SPM fraction than P2 fraction. NGL2-KO mice, however, showed an almost comparable intensity and pattern of immunosignals for netrin-G2 in immunohistochemical analysis (Fig. 8F). The discrepancy between biochemical and immunohistochemical analyses for netrin-G2 may reflect the powerful signal amplification effects of the method used. Alternatively, relative amounts of membrane-bound and unbound (secreted) isoforms of netrin-G2 could be changed in NGL2-KO mice. In any case, these findings indicate that the transsynaptic netrin-G/NGL interactions not only localize, but also stabilize, netrin-Gs at the presynaptic sites (Fig. 9A).

\section{Discussion}

Netrin-G1 and netrin-G2 are expressed throughout the brain in distinct but complementary regions (Yaguchi et al., 2014), and they form specific molecular complexes with NGL1 and NGL2, respectively. We provide evidence that netrin-Gs and NGLs localize at presynaptic and postsynaptic membranes, respectively, and that transsynaptic netrin-G/NGL interactions play a crucial role in differentially controlling synaptic plasticity in distinct excitatory circuits in the hippocampus.
A

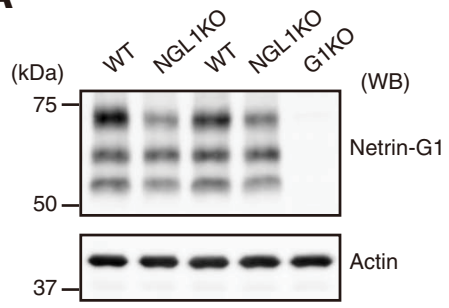

B
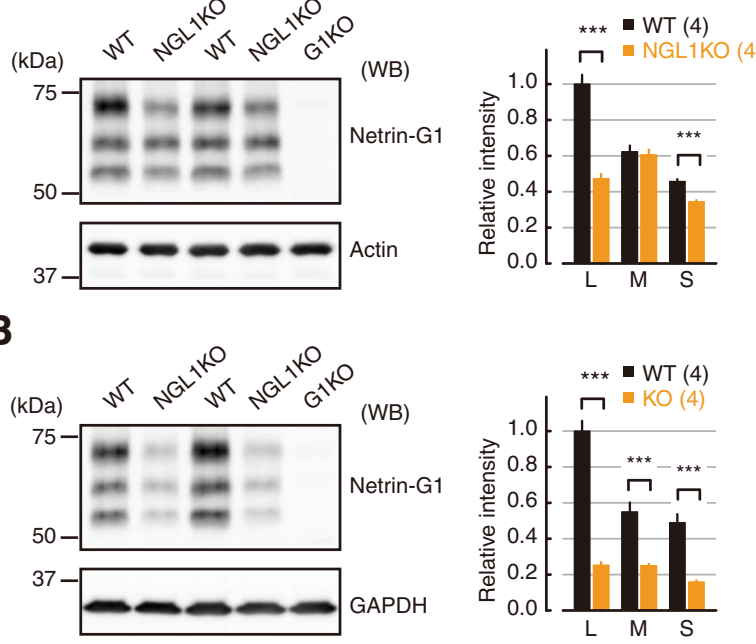

c

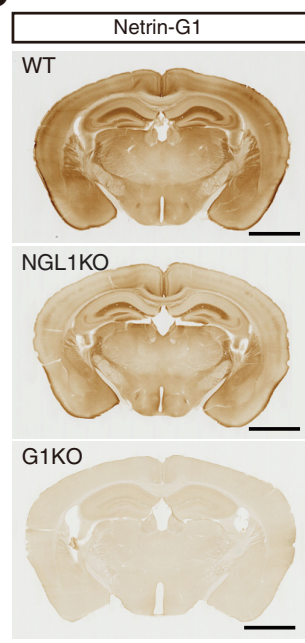

D
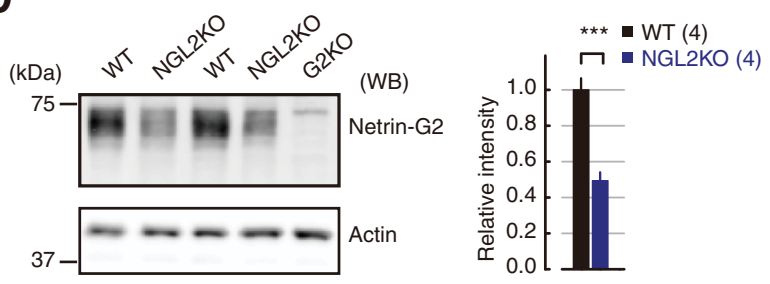

$\mathbf{F}$
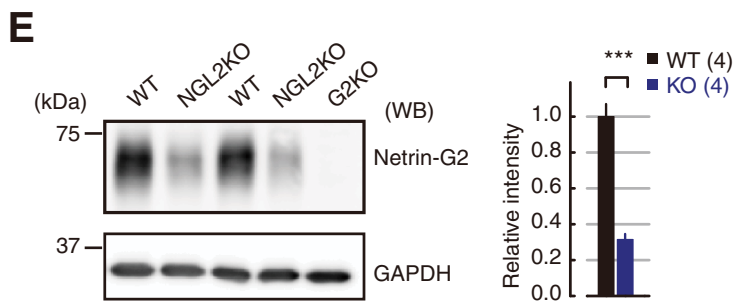

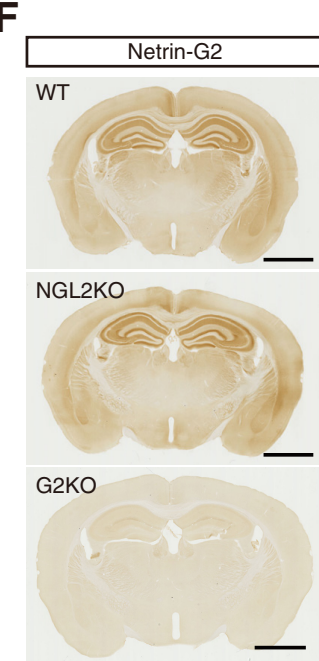

Figure 8. Synaptic localization and surface expression levels of netrin-Gs regulated by postsynaptic NGLs. Amounts of netrin-Gs were compared between NGL-KO and WT mice, in both P2 and SPM fractions from forebrains. $A$, WB of P2proteins probed with antibodies against netrin-G1 and actin in WT, NGL1-K0, and netrin-G1-K0 mice. Relative amounts of netrin-G1 isoforms were normalized with the long form of WT. P2-netrin-G1 was downregulated in NGL1-KO for long isoform (L) and short isoform (S), but not middle isoform (M). $B$, WB of SPM-proteins probed with antibodies against netrin-G1 and GAPDH in WT, NGL1-K0, and netrin-G1-KO mice. All SPM-netrin-G1 isoforms including M were further downregulated in NGL1-KO. C, Immunohistochemistry with antibody against netrin-G1 revealed downregulation of netrin-G1 in NGL1-K0 mice. Netrin-G1-KO mouse brain revealed the specificity of immune signals. $D$, WB of P2-proteins probed with antibodies for netrin-G2 and actin in WT, NGL2-K0, and netrin-G2-KO mice. P2-netrin-G2 was downregulated in NGL2-KO. E, WB of SPM-proteins probed with antibodies for netrin-G2 and GAPDH in WT, NGL2-KO, and netrin-G2-KO mice. SPM-netrin-G2 was further downregulated in NGL2-K0. $\boldsymbol{F}$, Immunohistochemistry with netrin-G2 antibody showed no differences between WT and NGL2-KO mice. Netrin-G2-KO mouse brain revealed the specificity of immune signals. The number of animals used in each WB is shown in parentheses. Data are shown as mean \pm SEM. Student's $t$ test, ${ }^{* * *} p<$ 0.001. Scale bars: $2 \mathrm{~mm}$.

\section{Molecular interaction of netrin-Gs and NGLs guides synaptic transmission}

Loss of presynaptic netrin-Gs results in the mislocalization of NGLs throughout the entire dendritic tree (Nishimura-Akiyoshi et al., 2007). Our iEM and biochemical analyses of NGL-KO mice indicated that netrin-Gs required postsynaptic NGLs to be stably localized within presynaptic membranes for maintaining the synaptic integrity. Unlike NGLs in netrin-G-KO mice (NishimuraAkiyoshi et al., 2007), netrin-G1 and netrin-G2 proteins were significantly reduced in NGL1-KO and NGL2-KO mice, respectively.
In vitro experiments suggest that the lack of netrin-G/NGL interactions causes deficits in synaptogenesis (Kim et al., 2006). An in vivo study revealed reduced synapse density in the CA1 of NGL2-KO juvenile mice, suggesting a role of netrin-G2/NGL2 interactions in synapse formation (DeNardo et al., 2012). No morphologic abnormalities, however, were evident in the CA1 of adult netrin-G KO mice. Moreover, we observed unaltered basal synaptic transmission in CA1 circuits in both netrin-G-KO mice. Unlike DeNardo et al. (2012), we observed normal synaptic transmission in the CA1 circuits of our adult NGL2-KO mice. We also observed no differences in CA1 pyramidal neuron spine den- 
A
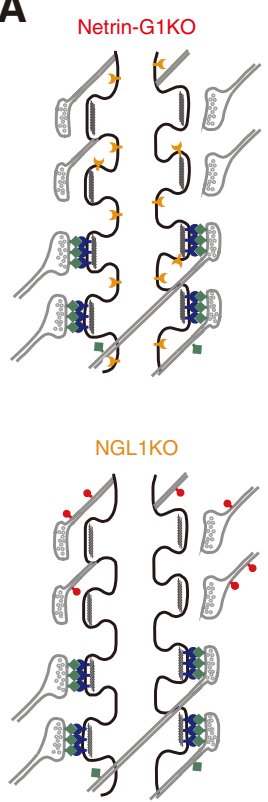
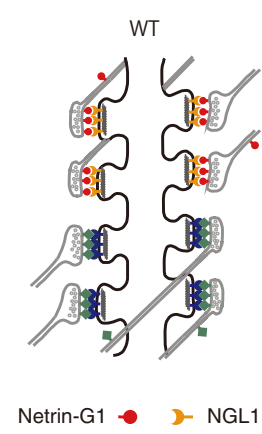

Netrin-G2 $>$ - NGL2

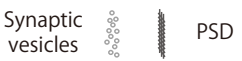

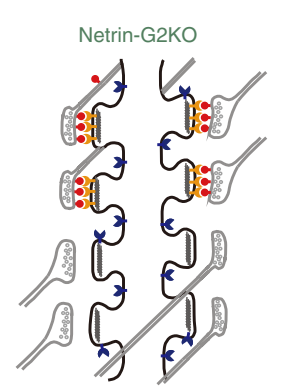

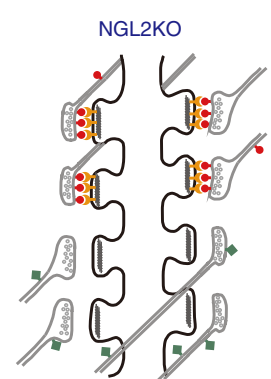

B
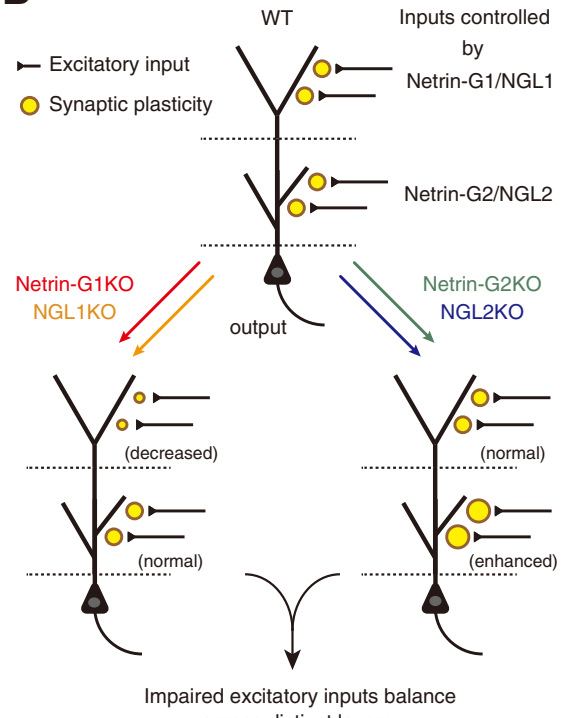

across distinct layers

Figure 9. Model for reciprocal localization of netrin-Gs and NGLs at synaptic contacts and their contribution to neural pathway-specific synaptic diversification. $A$, Schematic depiction of the localization of netrin-Gs and NGLs in mutant mice lacking netrin-G1, netrin-G2, NGL1, and NGL2, respectively. In netrin-G1 and netrin-G2 mutant mice, NGL1 and NGL2, respectively, diffuse from postsynaptic membranes. Likewise, in the absence of NGL1 and NGL2, respectively, netrin-G1 and netrin-G2 diffuse to axonal membranes. B, Trans-synaptic netrin-G1/NGL1 and netrin-G2/NGL2 interactions differentially control synaptic plasticity in a pathway-specific manner. Loss of the netrin-G1/NGL1 interaction attenuates synaptic plasticity (red/orange arrows). In contrast, loss of netrin-G2/NGL2 interaction enhances synaptic plasticity (green/blue arrows). Altered presynaptic function (PPR, and PTP) due to deletion of NGLs suggests their roles in retrograde signaling (postsynaptic NGLs $\rightarrow$ presynaptic netrin-Gs). Postsynaptic function(s) may be also regulated by forward signaling (presynaptic netrin-Gs $\rightarrow$ postsynaptic NGLs). Thus, netrin-G and NGLs interactions control the balance of excitatory inputs in distinct cortical layers for pathway-specific neuronal computation.

sities in both netrin-G2-KO and NGL2-KO mice at both P14 and adults. The discrepancy in the phenotypes may be due in part to differences in genetic backgrounds of mice, and needs to be addressed in the future.

NGLs potentially form a macromolecular complex with NMDARs and other postsynaptic molecules via scaffolding proteins, PSD-95, PSD-93, SAP102, and SAP97, which are abundantly localized at the PSDs of excitatory synapses (Kim et al., 2006). The associations are mediated via the C-terminal PDZbinding motif, which is common to both NGL1 and NGL2 (Lin et al., 2003). Mutant mouse studies demonstrated that these PSD proteins exert distinct roles in LTP induction, e.g., both PSD-95-KO and SAP-102-KO mice show enhanced LTP, while PSD-93-KO mice have impaired LTP (Migaud et al., 1998; Béïque et al., 2006; Cuthbert et al., 2007; Carlisle et al., 2008). Additionally, whirlin, a PDZ domain-containing adaptor protein, binds the C-terminal PDZ domain of NGL1 (Delprat et al., 2005). Whirlin is expressed in various tissues, including the brain, and is involved in actin polymerization in hair cells (Mburu et al., 2003; van Wijk et al., 2006). The lack of netrin-G1 and netrin-G2 might disturb the protein-protein network at a circuit-specific PSD environment due to the resultant removal of NGLs from postsynaptic structures (Nishimura-Akiyoshi et al., 2007). Imbalance and/or mislocalization of NGLs-associating PSD proteins in a specific circuit (a subdendritic segment) may explain some of the mechanisms underlying differential LTP abnormalities between netrin-G1-KO and netrin-G2-KO mice (Fig. 4). Postsynaptic NGLs might be involved in membranous remodeling of the spines mediated by a dynamic transition in equilibrium between F-actin and G-actin, which is correlated with the expression of long-term plasticity (Okamoto et al., 2004). Pre- cise roles of netrin-G/NGL/PSD interactions at the PSD environment remain to be determined.

\section{Netrin-G1/NGL1 and netrin-G2/NGL2 interactions diversify presynaptic plasticity}

Basal synaptic transmission and short-term plasticity evoked by paired stimuli in hippocampal CA1 circuits were not obviously altered in netrin-G1-KO or netrin-G2-KO mice (Fig. 2). Repetitive synaptic stimulations, such as TBuS and tetanus, applied to CA1 subregions produced opposing synaptic phenotypes between netrin-G1-KO and netrin-G2-KO mice (Figs. 3-5). How are these netrin-G/NGL interactions involved in the induction of such activity-dependent synaptic efficacy modulations? At TACA1 synapses of netrin-G1-KO mice, PTP, PTBuP, and LTP were all attenuated. On the other hand, at SC-CA1 synapses of netrinG2-KO mice, PTP, PTBuP, and LTP were all enhanced. PTP is widely accepted as a short-term plasticity induced by presynaptic mechanisms (Zucker and Regehr, 2002; Fioravante et al., 2011). Consistency in the directions of the abnormalities may suggest that the same presynaptic mechanism underlies the short-term and long-term plasticity. This notion was supported by observations during TBuS to induce LTP, in which EPSPs were attenuated in netrin-G1-KO TA-CA1, but enhanced in netrin-G2-KO SC-CA1.

Pharmacologic experiments suggested that presynaptic netrin-G1 is coupled with PKC signaling. Netrin-G1 might be involved in the process of $\mathrm{PKC}$ translocation onto the juxtamembrane or regulation of the PKC target(s), such as SNAP-25, munc-18, and $\mathrm{Ca}^{2+}$ channels, which have crucial roles in release mechanisms (Nagy et al., 2002; Lou et al., 2005; Korogod et al., 2007; Wierda et al., 2007; Shu et al., 2008). A novel cis-binding partner for netrin-G1/NGL1, LAR, might have an important role in this mechanism as a signal transducer, as netrin-G1 has no 
cytoplasmic domain. LAR possesses two tyrosine phosphatase domains (D1 and D2). D1 is catalytically active, whereas D2 is inactive but can physically interact with liprin- $\alpha$ and $\beta$-catenin (Serra-Pagès et al., 1995; Kypta et al., 1996). As demonstrated in dissociated hippocampal neurons, cis-interactions between netrin-G1 and LAR are required for presynaptic differentiation, but are independent of LAR phosphatase activity (Song et al., 2013). Liprin- $\alpha$ is an especially important binding partner of LAR and implicated in active zone assembly (Zhen and Jin, 1999; Kaufmann et al., 2002; Dai et al., 2006). Thus, the netrin-G1/ NGL1/LAR complex might situate vesicle fusion machineries near vesicular release sites and control accessibility of these proteins to PKC depending on synaptic activity.

Netrin-G2 is also coupled to a neuronal activity-dependent biochemical pathway that differs from the netrin-G1-dependent pathway at the TA-CA1 synapses. Netrin-G2-KO SC-CA1 synapses exhibited facilitated PTP, PTBuP, and LTP. PDBu induced no difference between netrin-G2-KO and control mice. Interestingly, the netrin-G2-KO SC-CA1 synapses showed impaired PPF under the forskolin treatment, while no differences were noted under naive conditions. Forskolin treatment abolished the PPD phenotype in netrin-G2-KO MPP-DG synapses (Fig. 3). These findings suggest that netrin-G2 has a role in regulating presynaptic mechanisms involving cAMP. The cAMP-signaling cascade has a crucial role in release machineries (Lu et al., 2006). A GPIlinked isoform of the IgD receptor mediates $\mathrm{B}$-cell activation through cAMP-dependent signaling pathways (Chaturvedi et al., 2002). Ephrin-A family members are GPI-anchored cell adhesion molecules that associate in cis with two different BDNF receptors, TrkB and p75NTR, which are type I transmembrane proteins that regulate axon elongation and retraction, respectively (Lim et al., 2008; Marler et al., 2008). Thus, we hypothesize that the opposite presynaptic phenotypes between netrin-G1-KO and netrin$\mathrm{G} 2-\mathrm{KO}$ mice are due to the biochemical properties of the specific cis-partners. Future studies aimed at identifying the predicted cis-binding partners will help to clarify the mechanisms depending on presynaptic netrin-Gs in transmitter release and presynaptic plasticity.

The presynaptic plasticity is regulated by a retrograde mechanism of netrin-G/NGL interaction. A similar mechanism for regulating presynaptic release machineries has been suggested in the neurexin/neuroligin system (Futai et al., 2007). Among related systems, the netrin-G/NGL system is unique in its role to control differentially distinct excitatory inputs for integrating information into a single cell (Fig. 9B).

\section{Netrin-G/NGL trans-synaptic interactions specify circuit properties}

Netrin-Gs/NGLs trans-synaptic interactions have regulatory roles in hippocampal synaptic transmission and plasticity (Figs. 2-5). LTP is generally believed to be the basis for information storage, such as episodic memory (Rumpel et al., 2005; Whitlock et al., 2006). PTP is also thought to influence working memory and information processing (Silva et al., 1996; Abbott and Regehr, 2004). In hippocampal and cortical laminar structures, principal neurons widely extend their dendritic branches, traversing multiple laminar structures and allowing them to receive distinct information flows. These distinct synaptic inputs are precisely integrated within the arborized dendrite architectures for generating output spiking (Spruston, 2008). Input location is a key factor for interactions across parallel distinct layers. For example, distal inputs alone only slightly affect somatic spikes, but can modulate proximal input for neuronal output (Remondes and Schuman, 2002; Larkum et al., 2004; Dudman et al., 2007). Thus, the relative balance between parallel excitatory inputs is likely critical to associatively optimize the mode of somatic output. Altered remodeling function of the input strength contributes to aberrant modulation of the output. In mouse brain, netrin-G1 is strongly expressed in distal laminar layers, while netrin-G2 is preferentially expressed in the proximal layers (Nishimura-Akiyoshi et al., 2007). The anatomic characteristics suggest that netrin-G1/NGL1 interactions serve as an intermodule regulator, while netrin-G2/NGL2 interactions serve as an intramodule regulator.

The results of our study indicate that netrin-G1/NGL1 and netrin-G2/NGL2 interactions trans-synaptically and differentially regulate synaptic plasticity of selective excitatory inputs. This netrin-G code for synaptic plasticity offers insight into how diversity in neural circuits is generated (Fig. 9B).

By acquiring differential expression patterns of paralogs netrin-G1 and netrin-G2 and having one-to-one relationships with binding partners, these ligand/receptor pairs had unique roles in elaborating higher vertebrate brain function. Several human studies suggest the involvement of netrin-Gs in mental and neurologic disorders, such as schizophrenia (Aoki-Suzuki et al., 2005), bipolar disease (Eastwood and Harrison, 2008), and autism (O'Roak et al., 2012). Further studies are needed to determine how the interactions integrate distinct information.

\section{References}

Abbott LF, Regehr WG (2004) Synaptic computation. Nature 431:796-803. CrossRef Medline

Aoki-Suzuki M, Yamada K, Meerabux J, Iwayama-Shigeno Y, Ohba H, Iwamoto K, Takao H, Toyota T, Suto Y, Nakatani N, Dean B, Nishimura S, Seki K, Kato T, Itohara S, Nishikawa T, Yoshikawa T (2005) A familybased association study and gene expression analyses of netrin-G1 and -G2 genes in schizophrenia. Biol Psychiatry 57:382-393. CrossRef Medline

Beierlein M, Fioravante D, Regehr WG (2007) Differential expression of posttetanic potentiation and retrograde signaling mediate targetdependent short-term synaptic plasticity. Neuron 54:949-959. CrossRef Medline

Béïque JC, Lin DT, Kang MG, Aizawa H, Takamiya K, Huganir RL (2006) Synapse-specific regulation of AMPA receptor function by PSD-95. Proc Natl Acad Sci U S A 103:19535-19540. CrossRef Medline

Blundell J, Blaiss CA, Etherton MR, Espinosa F, Tabuchi K, Walz C, Bolliger MF, Südhof TC, Powell CM (2010) Neuroligin-1 deletion results in impaired spatial memory and increased repetitive behavior. J Neurosci 30: 2115-2129. CrossRef Medline

Brager DH, Cai X, Thompson SM (2003) Activity-dependent activation of presynaptic protein kinase $\mathrm{C}$ mediates post-tetanic potentiation. Nat Neurosci 6:551-552. CrossRef Medline

Carlisle HJ, Fink AE, Grant SG, O’Dell TJ (2008) Opposing effects of PSD-93 and PSD-95 on long-term potentiation and spike timingdependent plasticity. J Physiol 586:5885-5900. CrossRef Medline

Chaturvedi A, Siddiqui Z, Bayiroglu F, Rao KV (2002) A GPI-linked isoform of the IgD receptor regulates resting B cell activation. Nat Immunol 3:951-957. CrossRef Medline

Chavez-Noriega LE, Stevens CF (1994) Increased transmitter release at excitatory synapses produced by direct activation of adenylate cyclase in rat hippocampal slices. J Neurosci 14:310-317. Medline

Chubykin AA, Atasoy D, Etherton MR, Brose N, Kavalali ET, Gibson JR, Südhof TC (2007) Activity-dependent validation of excitatory versus inhibitory synapses by neuroligin-1 versus neuroligin-2. Neuron 54:919931. CrossRef Medline

Cuthbert PC, Stanford LE, Coba MP, Ainge JA, Fink AE, Opazo P, Delgado JY, Komiyama NH, O’Dell TJ, Grant SG (2007) Synapse-associated protein 102/dlgh3 couples the NMDA receptor to specific plasticity pathways and learning strategies. J Neurosci 27:2673-2682. CrossRef Medline

Dai Y, Taru H, Deken SL, Grill B, Ackley B, Nonet ML, Jin Y (2006) SYD-2 Liprin-alpha organizes presynaptic active zone formation through ELKS. Nat Neurosci 9:1479-1487. CrossRef Medline 
Dalva MB, McClelland AC, Kayser MS (2007) Cell adhesion molecules: signalling functions at the synapse. Nat Rev Neurosci 8:206-220. CrossRef Medline

Delprat B, Michel V, Goodyear R, Yamasaki Y, Michalski N, El-Amraoui A, Perfettini I, Legrain P, Richardson G, Hardelin JP, Petit C (2005) Myosin XVa and whirlin, two deafness gene products required for hair bundle growth, are located at the stereocilia tips and interact directly. Hum Mol Genet 14:401-410. CrossRef Medline

DeNardo LA, de Wit J, Otto-Hitt S, Ghosh A (2012) NGL-2 regulates inputspecific synapse development in CA1 pyramidal neurons. Neuron 76: 762-775. CrossRef Medline

Dudman JT, Tsay D, Siegelbaum SA (2007) A role for synaptic inputs at distal dendrites: instructive signals for hippocampal long-term plasticity. Neuron 56:866-879. CrossRef Medline

Eastwood SL, Harrison PJ (2008) Decreased mRNA expression of netrin-G1 and netrin-G2 in the temporal lobe in schizophrenia and bipolar disorder. Neuropsychopharmacology 33:933-945. CrossRef Medline

Fioravante D, Chu Y, Myoga MH, Leitges M, Regehr WG (2011) Calciumdependent isoforms of protein kinase $\mathrm{C}$ mediate posttetanic potentiation at the calyx of Held. Neuron 70:1005-1019. CrossRef Medline

Futai K, Kim MJ, Hashikawa T, Scheiffele P, Sheng M, Hayashi Y (2007) Retrograde modulation of presynaptic release probability through signaling mediated by PSD-95-neuroligin. Nat Neurosci 10:186-195. CrossRef Medline

Gan WB, Grutzendler J, Wong WT, Wong RO, Lichtman JW (2000) Multicolor "DiOlistic" labeling of the nervous system using lipophilic dye combinations. Neuron 27:219-225. CrossRef Medline

Han K, Kim E (2008) Synaptic adhesion molecules and PSD-95. Prog Neurobiol 84:263-283. CrossRef Medline

Hori T, Takai Y, Takahashi T (1999) Presynaptic mechanism for phorbol ester-induced synaptic potentiation. J Neurosci 19:7262-7267. Medline

Huang CC, Hsu KS (2006) Presynaptic mechanism underlying cAMPinduced synaptic potentiation in medial prefrontal cortex pyramidal neurons. Mol Pharmacol 69:846-856. Medline

Kaneko M, Takahashi T (2004) Presynaptic mechanism underlying cAMPdependent synaptic potentiation. J Neurosci 24:5202-5208. CrossRef Medline

Kaufmann N, DeProto J, Ranjan R, Wan H, Van Vactor D (2002) Drosophila liprin-alpha and the receptor phosphatase Dlar control synapse morphogenesis. Neuron 34:27-38. CrossRef Medline

Kawase E, Suemori H, Takahashi N, Okazaki K, Hashimoto K, Nakatsuji N (1994) Strain difference in establishment of mouse embryonic stem (ES) cell lines. Int J Dev Biol 38:385-390. Medline

Kim S, Burette A, Chung HS, Kwon SK, Woo J, Lee HW, Kim K, Kim H, Weinberg RJ, Kim E (2006) NGL family PSD-95-interacting adhesion molecules regulate excitatory synapse formation. Nat Neurosci 9:12941301. CrossRef Medline

Korogod N, Lou X, Schneggenburger R (2007) Posttetanic potentiation critically depends on an enhanced $\mathrm{Ca}(2+)$ sensitivity of vesicle fusion mediated by presynaptic PKC. Proc Natl Acad Sci U S A 104:1592315928. CrossRef Medline

Kypta RM, Su H, Reichardt LF (1996) Association between a transmembrane protein tyrosine phosphatase and the cadherin-catenin complex. J Cell Biol 134:1519-1529. CrossRef Medline

Larkum ME, Senn W, Lüscher HR (2004) Top-down dendritic input increases the gain of layer 5 pyramidal neurons. Cereb Cortex 14:10591070. CrossRef Medline

Lee D, Lee KH, Ho WK, Lee SH (2007) Target cell-specific involvement of presynaptic mitochondria in post-tetanic potentiation at hippocampal mossy fiber synapses. J Neurosci 27:13603-13613. CrossRef Medline

Lim YS, McLaughlin T, Sung TC, Santiago A, Lee KF, O'Leary DD (2008) p75(NTR) mediates ephrin-A reverse signaling required for axon repulsion and mapping. Neuron 59:746-758. CrossRef Medline

Lin JC, Ho WH, Gurney A, Rosenthal A (2003) The netrin-G1 ligand NGL-1 promotes the outgrowth of thalamocortical axons. Nat Neurosci 6:1270-1276. CrossRef Medline

Lou X, Scheuss V, Schneggenburger R (2005) Allosteric modulation of the presynaptic Ca2+ sensor for vesicle fusion. Nature 435:497-501. CrossRef Medline

Lou X, Korogod N, Brose N, Schneggenburger R (2008) Phorbol esters modulate spontaneous and $\mathrm{Ca} 2+$-evoked transmitter release via acting on both Munc13 and protein kinase C. J Neurosci 28:8257-8267. CrossRef Medline

Lu HC, Butts DA, Kaeser PS, She WC, Janz R, Crair MC (2006) Role of efficient neurotransmitter release in barrel map development. J Neurosci 26:2692-2703. CrossRef Medline

Malenka RC, Madison DV, Nicoll RA (1986) Potentiation of synaptic transmission in the hippocampus by phorbol esters. Nature 321:175-177. CrossRef Medline

Marler KJ, Becker-Barroso E, Martínez A, Llovera M, Wentzel C, Poopalasundaram S, Hindges R, Soriano E, Comella J, Drescher U (2008) A TrkB/EphrinA interaction controls retinal axon branching and synaptogenesis. J Neurosci 28:12700-12712. CrossRef Medline

Mataga N, Mizuguchi Y, Hensch TK (2004) Experience-dependent pruning of dendritic spines in visual cortex by tissue plasminogen activator. Neuron 44:1031-1041. CrossRef Medline

Mburu P, Mustapha M, Varela A, Weil D, El-Amraoui A, Holme RH, Rump A, Hardisty RE, Blanchard S, Coimbra RS, Perfettini I, Parkinson N, Mallon AM, Glenister P, Rogers MJ, Paige AJ, Moir L, Clay J, Rosenthal A, Liu XZ, et al. (2003) Defects in whirlin, a PDZ domain molecule involved in stereocilia elongation, cause deafness in the whirler mouse and families with DFNB31. Nat Genet 34:421-428. CrossRef Medline

Migaud M, Charlesworth P, Dempster M, Webster LC, Watabe AM, Makhinson M, He Y, Ramsay MF, Morris RG, Morrison JH, O’Dell TJ, Grant SG (1998) Enhanced long-term potentiation and impaired learning in mice with mutant postsynaptic density-95 protein. Nature 396:433-439. CrossRef Medline

Nagy G, Matti U, Nehring RB, Binz T, Rettig J, Neher E, Sørensen JB (2002) Protein kinase C-dependent phosphorylation of synaptosome-associated protein of $25 \mathrm{kDa}$ at Ser 187 potentiates vesicle recruitment. J Neurosci 22:9278-9286. Medline

Nakashiba T, Ikeda T, Nishimura S, Tashiro K, Honjo T, Culotti JG, Itohara S (2000) Netrin-G1: a novel glycosyl phosphatidylinositol-linked mammalian netrin that is functionally divergent from classical netrins. J Neurosci 20:6540-6550. Medline

Nakashiba T, Nishimura S, Ikeda T, Itohara S (2002) Complementary expression and neurite outgrowth activity of netrin-G subfamily members. Mech Dev 111:47-60. CrossRef Medline

Niimi K, Nishimura-Akiyoshi S, Nakashiba T, Itohara S (2007) Monoclonal antibodies discriminating netrin-G1 and netrin-G2 neuronal pathways. J Neuroimmunol 192:99-104. CrossRef Medline

Nishimura-Akiyoshi S, Niimi K, Nakashiba T, Itohara S (2007) Axonal netrin-Gs transneuronally determine lamina-specific subdendritic segments. Proc Natl Acad Sci U S A 104:14801-14806. CrossRef Medline

Okamoto K, Nagai T, Miyawaki A, Hayashi Y (2004) Rapid and persistent modulation of actin dynamics regulates postsynaptic reorganization underlying bidirectional plasticity. Nat Neurosci 7:1104-1112. CrossRef Medline

O’Roak BJ, Vives L, Girirajan S, Karakoc E, Krumm N, Coe BP, Levy R, Ko A, Lee C, Smith JD, Turner EH, Stanaway IB, Vernot B, Malig M, Baker C, Reilly B, Akey JM, Borenstein E, Rieder MJ, Nickerson DA, et al. (2012) Sporadic autism exomes reveal a highly interconnected protein network of de novo mutations. Nature 485:246-250. CrossRef Medline

Otmakhova NA, Otmakhov N, Lisman JE (2002) Pathway-specific properties of AMPA and NMDA-mediated transmission in CA1 hippocampal pyramidal cells. J Neurosci 22:1199-1207. Medline

Remondes M, Schuman EM (2002) Direct cortical input modulates plasticity and spiking in CA1 pyramidal neurons. Nature 416:736-740. CrossRef Medline

Rumpel S, LeDoux J, Zador A, Malinow R (2005) Postsynaptic receptor trafficking underlying a form of associative learning. Science 308:83-88. CrossRef Medline

Sakaba T, Neher E (2001) Preferential potentiation of fast-releasing synaptic vesicles by cAMP at the calyx of Held. Proc Natl Acad Sci U S A 98: 331-336. CrossRef Medline

Seiradake E, Coles CH, Perestenko PV, Harlos K, McIlhinney RA, Aricescu AR, Jones EY (2011) Structural basis for cell surface patterning through NetrinG-NGL interactions. EMBO J 30:4479-4488. CrossRef Medline

Serra-PagèsC, Kedersha NL, Fazikas L, Medley Q, Debant A, Streuli M (1995) The LAR transmembrane protein tyrosine phosphatase and a coiled-coil LAR-interacting protein co-localize at focal adhesions. EMBO J 14:2827-2838. Medline

Shapira R, Silberberg SD, Ginsburg S, Rahamimoff R (1987) Activation of 
protein kinase $\mathrm{C}$ augments evoked transmitter release. Nature 325:58-60. CrossRef Medline

Sheng M, Kim E (2011) The postsynaptic organization of synapses. Cold Spring Harb Perspect Biol 3:a005678. CrossRef Medline

Shimuta M, Yoshikawa M, Fukaya M, Watanabe M, Takeshima H, Manabe T (2001) Postsynaptic modulation of AMPA receptor-mediated synaptic responses and LTP by the type 3 ryanodine receptor. Mol Cell Neurosci 17:921-930. CrossRef Medline

Shu Y, Liu X, Yang Y, Takahashi M, Gillis KD (2008) Phosphorylation of SNAP-25 at Ser187 mediates enhancement of exocytosis by a phorbol ester in INS-1 cells. J Neurosci 28:21-30. CrossRef Medline

Siddiqui TJ, Craig AM (2011) Synaptic organizing complexes. Curr Opin Neurobiol 21:132-143. CrossRef Medline

Silva AJ, Rosahl TW, Chapman PF, Marowitz Z, Friedman E, Frankland PW, Cestari V, Cioffi D, Südhof TC, Bourtchuladze R (1996) Impaired learning in mice with abnormal short-lived plasticity. Curr Biol 6:1509-1518. CrossRef Medline

Song YS, Lee HJ, Prosselkov P, Itohara S, Kim E (2013) Trans-induced cis interaction in the tripartite NGL-1, netrin-G1 and LAR adhesion complex promotes development of excitatory synapses. J Cell Sci 126:4926-4938. CrossRef Medline

Spruston N (2008) Pyramidal neurons: dendritic structure and synaptic integration. Nat Rev Neurosci 9:206-221. CrossRef Medline

Südhof TC (2012) The presynaptic active zone. Neuron 75:11-25. CrossRef Medline

van Wijk E, van der Zwaag B, Peters T, Zimmermann U, Te Brinke H, Kersten FF, Marker T, Aller E, Hoefsloot LH, Cremers CW, Cremers FP, Wolfrum
U, Knipper M, Roepman R, Kremer H (2006) The DFNB31 gene product whirlin connects to the Usher protein network in the cochlea and retina by direct association with USH2A and VLGR1. Hum Mol Genet 15:751-765. CrossRef Medline

Whitlock JR, Heynen AJ, Shuler MG, Bear MF (2006) Learning induces long-term potentiation in the hippocampus. Science 313:1093-1097. CrossRef Medline

Wierda KD, Toonen RF, de Wit H, Brussaard AB, Verhage M (2007) Interdependence of PKC-dependent and PKC-independent pathways for presynaptic plasticity. Neuron 54:275-290. CrossRef Medline

Woo J, Kwon SK, Kim E (2009) The NGL family of leucine-rich repeatcontaining synaptic adhesion molecules. Mol Cell Neurosci 42:1-10. CrossRef Medline

Yaguchi K, Nishimura-Akiyoshi S, Kuroki S, Onodera T, Itohara S (2014) Identification of transcriptional regulatory elements for Ntng1 and Ntng2 genes in mice. Mol Brain 7:19. CrossRef Medline

Yamagata M, Sanes JR, Weiner JA (2003) Synaptic adhesion molecules. Curr Opin Cell Biol 15:621-632. CrossRef Medline

Yin Y, Miner JH, Sanes JR (2002) Laminets: laminin- and netrin-related genes expressed in distinct neuronal subsets. Mol Cell Neurosci 19:344358. CrossRef Medline

Zhen M, Jin Y (1999) The liprin protein SYD-2 regulates the differentiation of presynaptic termini in C. elegans. Nature 401:371-375. CrossRef Medline

Zucker RS, Regehr WG (2002) Short-term synaptic plasticity. Annu Rev Physiol 64:355-405. CrossRef Medline 